\title{
EL CRECIMIENTO DE LAS GRANDES EMPRESAS LATINOAMERICANAS DESDE LOS AÑOS '70 *
}

Gustavo Burachik **

\begin{abstract}
Resumen
El artículo analiza el crecimiento de las grandes empresas latinoamericanas de capital local desde la década del '70. Se propone un esquema conceptual para abordar esta cuestión basado en la distinción entre la disponibilidad de fondos para invertir y el acceso a oportunidades efectivas de crecimiento. El trabajo se abastece del material surgido de una amplia reseña bibliográfica pero su objetivo principal consiste en ordenar y articular la evidencia relevada en conformidad con el esquema teórico propuesto.
\end{abstract}

Clasificación JEL: O16, P12, P16

Palabras clave: crecimiento de la empresa - grandes empresas - capital extranjero

\begin{abstract}
This article analyses the growth pattern shown by large Latin-American domestic-capital firms since the '70s. A framework is suggested for dealing with this issue from a conceptual point of view. This framework rests on the distinction between firms ability for founding the growth process, on the one side, from that of getting access to investment opportunities, on the other. The essay collects its raw material from a wide literature review but its main objective is to both arrange and integrate the empirical evidence into the suggested theoretical framework.
\end{abstract}

Clasificación JEL: O16, P12, P16

Palabras clave: firm growth - large firms - foreign capital

\section{INTRODUCCION}

En los '80 y '90 se alteró la cantidad y orientación de los estudios sobre las grandes empresas diversificadas de los países semiindustrializados (psi). Por un lado, decayeron sensiblemente los esfuerzos de teorización, por el otro; se observó un notable aumento del caudal de estudios empíricos.

\footnotetext{
* El presente trabajo constituye el capítulo tercero de la tesis de Doctorado en Economía presentada por el autor en el Departamento de Graduados de la Universidad Nacional del Sur, Bahía Blanca, 2007.

*** Departamento de Economía, Universidad Nacional del Sur, e.mail: burachik@ criba.edu.ar
} 
La discontinuidad en materia de elaboración teórica se pone en evidencia en los esquemas analíticos invocados por los estudios empíricos. Los artículos de Leff siguen acaparando las referencias teóricas en la mayoría de los estudios sobre grandes empresas de los países atrasados realizados en la actualidad.

Pero, en paralelo con el decaimiento de la discusión teórica, tuvo lugar un brusco cambio de perspectiva para el abordaje del problema. En efecto, mientras que la obra de Merhav y la de Leff se insertaban (cada una a su modo) en la esfera de la teorización sobre las condiciones para el desarrollo capitalista en los países de industrialización tardía, los trabajos empíricos realizados en las últimas dos décadas se sitúan en el ámbito, más restringido, de la "teoría de la firma".

Aquí se ofrece un bosquejo de las principales características del crecimiento de las grandes empresas de América Latina (AL) desde los años '70. El texto reposa en los relativamente abundantes estudios de caso sobre grandes empresas y grupos económicos (en adelante, ge) en los distintos países y el material más general sobre la evolución de las economías de la región en las últimas tres décadas.

Antes de comentar la estructura temática de la exposición, son necesarias algunas definiciones y aclaraciones metodológicas. Lo que la literatura denomina como "gran empresa" de capital nacional, que adopta en todos los países de América latina la forma de conglomerado con intereses en la industria y otras actividades, constituye la unidad de análisis y es a veces referenciada como ge. Como es sabido, estas corporaciones experimentaron un crecimiento significativo en la masa de activos bajo su control desde los '70 hasta aproximadamente mediados de los '90 y un retroceso de sus inversiones en la industria y en los servicios en los años siguientes. En este artículo se estudia la anatomía interna de este proceso.

\section{ASPECTOS TEORICOS Y EMPIRICOS DEL ANALISIS DE LA ACUMULACION}

El desarrollo capitalista en los países industriales ha reposado desde sus comienzos en la constante mejora y revolución de las técnicas productivas y de los productos mismos. Además de modificar las características del proceso de trabajo, estos cambios se han expresado también en oleadas de ascenso y declinación de ramas enteras de actividad. Este aspecto del funcionamiento del capitalismo permite incluso trazar su evolución de largo plazo, entre otras cosas, como una sucesión de fases históricas impulsadas por un conjunto específico de negocios dinámicos.

Por otra parte, en cada fase los canales sectoriales y espaciales abiertos al capital resultan de la interacción de fuerzas contradictorias de impulso y freno, es decir, emergen tanto de las potencialidades del capital como de sus límites. La experiencia de los EE.UU. en la posguerra ofrece un buen ejemplo: enfrentadas con crecientes obstáculos a la reinversión en sus rubros originales, la expansión de las grandes empresas pasó a reposar en el desplazamiento del capital desde negocios maduros a otros más dinámicos y rentables, dentro y fuera de los EE.UU. Como resultado, se generalizaron la diversificación y 
conglomeración como formas de crecimiento mientras que la internacionalización del capital, que muchas compañías ya practicaban, se aceleró (Rumelt ,1974 y Chandler, 1982).

En su momento, estos canales de expansión ofrecieron una salida a una situación de exceso de fondos invertibles con relación a las oportunidades de inversión a disposición de las firmas en sus actividades tradicionales pero habrían de toparse, a su turno, con sus propios límites. Estos últimos resultaron claros en lo relativo a la diversificación. La mayoría de las empresas agotó rápidamente el reducido conjunto de oportunidades de diversificación rentable a su alcance (en rubros relacionados en los que pudiese hacer valer sus ventajas originales) y debió pasar particularmente en los '60) a una diversificación cada vez menos relacionada y rentable y crecientemente especulativa (Rumelt, op.cit. y Gaughan, 1999).

Se revela así una arista peculiar de este proceso. Antes de provocar una interrupción de la acumulación, la gradual maduración del conjunto de productos y tecnologías que había dinamizado la acumulación, forzó una masiva reorientación de los fondos invertibles a disposición de las firmas hacia nuevas alternativas, en muchos casos a costa de la rentabilidad. Esta evolución no resultaría inteligible si se prescindiese del carácter compulsivo de la acumulación y la competencia en el modo de producción capitalista. La crisis de la acumulación habría de llegar, recién en los '70 y, con mayor severidad, en los '80 (Gaughan, op.cit.).

La escisión conceptual entre, por un lado, la magnitud de los fondos a disposición de las firmas y, por el otro, la extensión de sus oportunidades de inversión rentable se revela como un procedimiento útil para describir la naturaleza de los obstáculos al crecimiento. Es como si, para concretar una inversión, las grandes corporaciones debieran contemplar dos problemáticas hasta cierto punto independientes. Por un lado, como es natural, deben acceder a fondos (propios o de terceros) en una magnitud adecuada. Por el otro, deben estar en condiciones de superar las barreras que obstaculizan el ingreso a las oportunidades relativamente rentables y, eventualmente, estar capacitadas para erigir trabas a la entrada de otras firmas.

De este modo, así como el proceso de acumulación tropieza con fuerzas que obstruyen el acceso de las empresas a los fondos requeridos (caída de los márgenes, restricción crediticia), encuentra también límites precisos en el ámbito de las oportunidades de inversión disponibles. Las compañías responden a la primera clase de barreras introduciendo cambios técnicos, organizativos, institucionales y políticos y reaccionan a las del segundo tipo buscando canales alternativos de expansión.

\section{DISPONIBILIDAD DE FONDOS}

Hubo un salto en el acceso de los ge a fondos disponibles para la acumulación que se materializó a través de los siguientes canales: el crédito (doméstico y externo), los subsidios estatales y los recursos propios (margen de beneficios). Por último, el propio 
proceso de expansión del tamaño de las grandes empresas operó como una fuerza autónoma en igual sentido ya que amplió su acceso a fondos propios y de terceros.

\section{II.1. Acceso al crédito}

Uno de los pilares fundamentales en que reposó la política de inversión y adquisiciones de empresas por parte de los ge en los ' 70 y ' 80 consistió en su acceso privilegiado al crédito en un contexto de crisis económica y financiera generalizada en sus respectivos países ${ }^{1}$. Esta ventaja reposó, a su vez, en una combinación (variable entre países) de los siguientes fenómenos.

a. el progreso de la centralización financiera

b. la apertura financiera de América Latina al crédito externo

\section{II.1. a. Integración con el capital financiero}

En algunos países en que los ge han experimentado un crecimiento acelerado en los '70 y ' 80 , este ha sido precedido por un proceso de centralización financiera junto con algún grado de integración entre el capital industrial y el bancario. Esta ha sido la secuencia, por ejemplo, en Chile. Allí, la privatización de las empresas estatizadas por el gobierno de Allende en 1970/73, con que se inició el despegue cuantitativo de los ge, tuvo lugar en 1975/77 en un contexto de aguda recesión. Esto limitaba la participación como compradores sólo a aquellas empresas que tuvieran acceso al crédito. Pero como el proceso de privatización se inició precisamente en el sector bancario, el reducido grupo de grandes compañías que los adquirió (con créditos concedidos por los propios bancos que estaban comprando) estuvo en condiciones de acaparar las subsiguientes des-estatizaciones (Sanfuentes, 1984; ver también Fernández Jilberto, 2004).

Con la reforma previsional chilena emprendida en la segunda mitad de los '80 (que puso a disposición de las empresas una masa de ahorro equivalente al $40 \%$ del pbi), la expansión de los fondos mutuos y de las compañías de seguros permitió un avance ulterior de la centralización ya que "permitió a los grupos más importantes disponer del control estrecho de muchas empresas, sin tener que copar la totalidad de su propiedad e incluso, en algunas grandes firmas, con un porcentaje minoritario" (Sanfuentes, 1984).

En México la centralización financiera no precedió a la primera fase de expansión de los ge (1977/82) pero fue, en cambio, una condición necesaria para el crecimiento que habrían de experimentar en los '90. En efecto, a principios de los '90 y gracias a la privatización de la banca que había sido nacionalizada a principios de la década anterior (como consecuencia de la crisis de la deuda) surgieron los grandes grupos financieros y financiero-industriales que experimentaron un significativo crecimiento en el país y en el exterior en los años subsiguientes. Según Garrido (1998) ese proceso de privatización

\footnotetext{
${ }^{1}$ Naturalmente, el acceso diferencial al financiamiento por parte de los ge constituyó una clave no sólo de la capacidad de expansión sino también, en muchos sectores, de la probabilidad de supervivencia (Moguillansky y Bielschowsky, 2001) ya que determina la capacidad de las empresas para mantener la edad media de los equipos.
} 
permitió a las grandes empresas alcanzar el salto de tamaño (capacidad financiera) requerido para operar e intentar crecer en el nuevo escenario de los ' 90.

Contribuyó también a la creciente concentración del crédito la eliminación, en varios países (Argentina, Chile, México y Perú), de organismos públicos que lo otorgaban con subsidios (Moguillansky y Bielschowsky, op.cit., 55).

\section{II.1. b. Acceso al financiamiento externo}

En los '70 tuvo lugar la primera experiencia de apertura financiera en América Latina. Como es sabido, la colocación de deuda en plazas financieras del exterior es una potestad restringida a los Estados y a las grandes empresas.

Así, desde los '70 se produjeron dos oleadas de endeudamiento externo de las grandes empresas de la región que reprodujeron las fluctuaciones experimentadas por los flujos de capital de corto plazo desde los países avanzados hacia América Latina. La primera tuvo lugar en los últimos años de la década del '70 y culminó en 1981. La segunda se inició a principios de los '90, luego de la renegociación de las deudas externas públicas latinoamericanas realizada en el marco del Plan Brady que permitió a los ge retornar al mercado voluntario de crédito internacional. Este nuevo acceso al mercado internacional de crédito, que comenzó a disminuir en 1996/97, resultó vital para la expansión de los ge en los 90 .

Es cierto que el acceso de los países de América Latina al endeudamiento externo repercutió favorablemente sobre la oferta de fondos por parte del sistema financiero doméstico. Pero, en la medida en que la discriminación de tasas y plazos en favor de las empresas de mayor tamaño inherente al funcionamiento de este mercado persistió, la mayor afluencia de crédito sólo benefició a las grandes corporaciones, nacionales y extranjeras.

\section{II.2. La acción estatal}

La acción estatal ha constituido siempre un pilar básico de la existencia y expansión de las grandes empresas en los psi y ha sido incorporada como tal en las teorizaciones. Si una particularidad puede señalarse respecto del período posterior al quiebre de la sustitución de importaciones es el carácter cada vez más abierto e intenso del apoyo del Estado a los ge en América Latina. Este apoyo circuló a través de dos tipos de canales. El primero son los subsidios directos como la estatización de los pasivos externos en los años '80 y las políticas (tributarias y financieras) de promoción de la inversión y las exportaciones y las de estímulo a la relocalización de plantas (Argentina y Brasil) que se vienen implementando en varios países desde esa época hasta nuestros días.

El segundo, lo conforman algunas de las principales medidas comprendidas por las llamadas políticas de reforma. En efecto, según se asegura en la literatura específica, la apertura y desregulación financiera han proporcionado el marco institucional requerido para el acceso de las grandes empresas de la región al mercado voluntario de crédito externo en 
los períodos de liquidez. Por su parte, el mantenimiento de estas condiciones, junto con la aceptación por parte de los gobiernos de la región de las políticas económicas reclamadas por los organismos internacionales que arbitran entre deudores y acreedores, han permitido restablecer el crédito del exterior luego de las sucesivas crisis financieras ocurridas en las últimas dos décadas. Además, las privatizaciones desempeñaron un doble y fundamental papel en el crecimiento de los ge. Por un lado, proporcionaron oportunidades para la aplicación rentable de fondos a gran escala ${ }^{2}$. Por el otro, en la medida en que permitieron a los beneficiarios un apreciable salto de tamaño, ampliaron su acceso a los fondos propios y de terceros requeridos para la supervivencia y la expansión en el escenario, más competitivo, de los ' $90^{3}$.

En suma, la preservación y consolidación de los ge de América Latina ha sido, en una medida considerable, el resultado de una larga serie de políticas estatales orientadas directa o indirectamente a dicho fin e implementadas con renovado vigor desde los años '70.

La experiencia de las grandes empresas mexicanas puede considerarse representativa de lo ocurrido con los ge de otros países de la región ${ }^{4}$. Según Garrido (2001) aquéllas no podrían haber avanzado hacia la internacionalización en los '90 de no haber sido por el apoyo estatal que recibieron a lo largo de las dos décadas previas a través de:

- la estatización de sus pasivos externos en los '80,

- el salto de escala y capacidad financiera que experimentaron como resultado de su participación en las privatizaciones del período 1986/94 \% así como en la desestatización de la banca mencionada en el inciso anterior

- el retorno al mercado voluntario de crédito externo obtenido gracias a la adhesión de México al Plan Brady a principios de los '90.

\section{3. Márgenes de beneficio}

Es preciso exponer los factores que afectaron los márgenes de beneficios de las grandes empresas teniendo en cuenta las características de las dos grandes etapas por las que atravesaron las economías de América Latina en las últimas tres décadas, es decir; antes y después de las llamadas "reformas estructurales".

II. 3.a. Evolución de los márgenes en un contexto de crisis interna

\footnotetext{
${ }^{2}$ Es por ello que este aspecto de las privatizaciones es tratado en el apartado III, donde se analiza el modo en que los ge aplicaron los fondos cuya ampliación se analiza aquí.

3 Esto, además del subsidio implícito en la transferencia de los activos públicos a las empresas como los que se derivaron de la aceptación de títulos de deuda externa como parte de pago reconocidos a un valor muy superior al de mercado, la subvaluación de los activos vendidos y la autorización de elevados márgenes operativos.

${ }^{4}$ Una descripción del apoyo estatal recibido por las grandes empresas chilenas puede encontrarse en Sanfuentes (1984) y Moguillansky y Bielschowsky (op cit: 39).

5 De cuya participación se encontraban expresamente excluidas las empresas extranjeras, excepto como socios tecnológicos.
} 
En las décadas del '70 y '80, tres factores permitieron a las grandes empresas reforzar sus márgenes de beneficio.

La redistribución inter-sectorial de riqueza adquirió una importancia crucial en el contexto de alta inflación que caracterizó al período de crisis económica y financiera por el que pasó América latina en los '70 y '80. Más aún, lejos de padecer los efectos desorganizadores de la elevada inflación, las empresas de mayor tamaño asumieron un papel activo en su estímulo y propagación y se situaron ventajosamente en el proceso resultante de la modificación de precios relativos.

En segundo lugar, las grandes empresas de América latina tendieron a volcarse, precisamente en este período, hacia las actividades de exportación. Es por ello que fueron beneficiarias de la subvaluación de las monedas (con el consiguiente encarecimiento relativo de los bienes transables) resultante, a su vez, de la crisis de balanza de pagos que tuvo lugar durante los años '80. La capacidad de exportación, además, interactuaba con el liderazgo en el mercado interno porque aquellas empresas que gozaban de acceso a mercados externos se encontraban en mejores condiciones para proteger sus márgenes de beneficio en un contexto de aguda recesión interna. Además, por ejemplo en Argentina, los elevados precios obtenidos por las ventas en el mercado interno contribuían a subsidiar las exportaciones.

En tercer lugar, en los países estudiados, los cambios introducidos en el mercado de trabajo y las instituciones que regulan las relaciones laborales deben haber jugado un papel importante como factor de sostenimiento y elevación de los márgenes de beneficio ${ }^{6}$. Estos cambios, que abrieron sin duda una nueva época en materia de relaciones laborales, permiten a las empresas elevar significativamente el valor producido por obrero, racionalizar personal y, por supuesto, disminuir el costo laboral real estableciendo ajustes nominales inferiores al encarecimiento de los productos elaborados. La racionalización e intensificación del esfuerzo laboral dio lugar, además, al proceso de tercerización y desverticalización de las grandes plantas. Ocurre que el recorte de puestos de trabajo se concentró en las tareas auxiliares y/o etapas específicas del proceso productivo que pasaron a ser contratados a proveedores o subcontratistas de menor tamaño, cuya fuerza de trabajo (escasamente sindicalizada, flexible y más barata) resulta alimentada por el propio proceso de racionalización de las grandes compañías.

Chile proporciona un buen ejemplo de reestructuración empresarial en que los cambios en el mercado de trabajo han jugado un papel central. En este país se ha difundido la formación de cadenas lideradas por grandes compañías (los fabricantes y en muchos casos los distribuidores o comercializadores) que abastecen el mercado interno subcontratando las tareas de producción a empresas de menor tamaño que ocupan fuerza de trabajo flexible. Según Díaz (1996), esto permite a las grandes empresas disminuir sus costos laborales, financieros e impositivos y eludir conflictos gremiales.

${ }^{6}$ Independientemente de la presión a la baja salarial que se derivaba del desequilibrio de dicho mercado ocasionado por la propia crisis económica. 
En varios países (Brasil, México y Argentina), las políticas de incentivo a la relocalización de plantas, permitieron a las empresas obtener simultáneamente una significativa disminución de sus costos laborales (ya que las regiones promovidas contaban con una oferta de trabajo no sindicalizada, flexible y más barata) y beneficios impositivos de distinto tipo ${ }^{7}$.

Como resultado de su capacidad para incrementar sus márgenes, las grandes empresas gozaron de un acceso privilegiado a la liquidez durante los años de crisis financiera y económica, en algunos países desde fines de los '70 y en otros desde principios de los '80. Esta ventaja reposaba, a su vez, en el control de la producción en los principales mercados de bienes y servicios, esto es, en la capacidad de las grandes empresas para sostener e incluso ampliar sus márgenes en un contexto de depresión de la demanda, tasas de interés reales positivas y elevadas y volatilidad de los precios relativos internos.

\section{3.b. Evolución de los márgenes en un contexto de apertura y aumento de la IED}

La mayoría de los estudios afirman que la apertura comercial implementada en América Latina en algunos países desde los '80 y en otros en los '90 dio lugar a una tendencia a la depresión de los márgenes en el conjunto de la producción de bienes transables. Ciertamente, en los '90 se tornaron más severas las condiciones de competencia en que operan las empresas de la región. Pero, al mismo tiempo, no puede ignorarse que las mismas "reformas" proporcionaron resquicios defensivos y oportunidades de crecimiento a los ge $\mathrm{e}^{8}$. Por un lado, porque consolidaron su crecimiento en actividades resguardadas de la competencia importada (servicios, negocios ligados a los recursos energéticos y commodities industriales y agroindustria).Por el otro, porque capitalizaron en beneficio propio la apertura, la apreciación cambiaria y los proyectos de integración regional a través de las siguientes estrategias:

-gracias a su control de las redes domésticas de comercialización y distribución, acordaron con potenciales competidores extranjeros importar artículos terminados (que estaban siendo producidos localmente con reducida rentabilidad), como complemento de la producción propia (que pasó a limitarse a las líneas más rentables); este procedimiento permite abastecer toda la gama de segmentos del mercado sin sacrificio del margen medio de beneficio

-sustituyeron componentes nacionales por otros importados más sofisticados, de mejor calidad, etc. para disminuir sus costos ${ }^{9}$.

Según se desprende de la literatura empírica consultada, se observa una tendencia de las grandes empresas de AL que abastecen al mercado interno a integrar espacialmente sus ventas, combinando o alternando exportaciones e importaciones (es decir; combinando fabricación con comercialización) según las coyunturas de sus países y de la región.

\footnotetext{
${ }^{7}$ Por ejemplo, una de las empresas brasileñas estudiadas por Quadros Carvalho y Bernardes (1998) pagaba en 1995 en su planta de Minha Gerais salarios medios 50\% más bajos que en su planta de San Pablo.

${ }_{8}$ Es por esto, precisamente, que estas políticas han acentuado el dualismo social y económico en todos los países de América Latina. Este punto se retomará más adelante.

${ }_{9}^{9}$ Por ejemplo, en Brasil, como resultado conjunto de medidas de este tipo y de intensificación del trabajo acompañadas por muy baja inversión, el producto por ocupado en la industria aumentó un 34\% entre 1991 y 1994 (Quadros Carvalho y Bernardes, op cit).
} 
Por ejemplo, según Díaz (op.cit.) en Chile, las empresas que operan en estos sectores tienen como base de sustentación el control del mercado interno con producción propia o importada y basan su crecimiento en la exportación. El control del mercado interno, por su parte, reposa sobre el predominio productivo y/o el liderazgo en la esfera de la distribución y comercialización. Lejos de constituir una amenaza para las grandes empresas que se encuentran en esta posición privilegiada, las importaciones pueden contribuir a afianzar sus ventajas porque proporcionan un acceso inmediato (que no siempre está disponible para las empresas más pequeñas) a insumos y componentes más productivos con cuyo concurso se mantiene o dilata la ventaja de costos y porque permite percibir rentas derivadas del control de la distribución y comercialización sin necesidad de extender la fabricación a toda las líneas de productos, incluidas aquellas para las cuales el mercado doméstico resulta demasiado pequeño ${ }^{10}$.

\section{II.3.4. Aumento de la escala}

Además de la creciente capacidad de las grandes empresas para ampliar su acceso a fondos disponibles para la inversión (determinada por los tres factores comentados más arriba), el propio proceso de acumulación de activos a que esto dio lugar operó en el mismo sentido. Efectivamente, toda la literatura reseñada coincide en afirmar que el incremento en la escala de los grupos ha actuado como un factor que potencia su acceso al crédito.

En suma, el apartado II procuró mostrar cómo, desde los años '70, las grandes empresas de la región tuvieron acceso a un flujo incrementado de fondos invertibles, propios y de terceros. Una multiplicidad de factores convergieron para que esto suceda; un aumento de la concentración que se tradujo en mayores márgenes, subsidios estatales, una mayor integración con el sistema financiero en sus países y las políticas que materializaron la incorporación de América Latina (básicamente de sus grandes empresas y sus Estados) al mercado financiero internacional. En el apartado III, que se desarrolla a continuación, se pasa revista a las principales esferas de aplicación de estos fondos.

\section{DESTINOS DE LA INVERSION}

En esta sección se ofrece una descripción de los principales usos a los que fueron destinados los crecientes fondos invertibles en poder de los ge desde los '70 y que pueden ser clasificados en tres grandes categorías: adquisición de activos productivos existentes, nueva inversión productiva y adquisición de activos (y disminución de pasivos) externos.

Como es sabido, la expansión de los ge tuvo lugar en un contexto de pobre desempeño agregado en la mayoría de los países de la región ${ }^{11}$. Es por ello que la mayor parte de aquél crecimiento no apuntó a expandir la oferta doméstica de bienes y servicios a

10 Acerca de esta misma tendencia en las grandes empresas de México, ver Casar (1996) y Garrido (1998). Sobre Argentina, ver Bisang y otros (1996).

${ }^{11}$ En el Anexo se ofrece un marco general de lo que ocurrió con la inversión en América latina desde los '80. 
ser demandados en estos países. Por una parte, porque el eje reposó en inversiones que no ampliaron sustancialmente la oferta doméstica de bienes y servicios. Por el otro, porque aquellas inversiones que incrementaron la capacidad productiva doméstica tendieron a orientar sus ventas hacia la exportación.

\section{III.1. Adquisición de activos existentes en sus respectivos países}

Gracias a la expansión experimentada en el flujo de fondos a su disposición (comentada en el apartado II), los ge se encontraron en condiciones de aprovechar las oportunidades de absorción de empresas existentes que se plantearon durante las últimas tres décadas.

Hubo dos conjuntos de fenómenos que tuvieron la capacidad de abrir amplias oportunidades de expansión a través de la centralización a las empresas más grandes de América Latina. El primero resultó de las crisis económicas y financieras ocurridas desde los '70 provocadas por distintas combinaciones de: programas de apertura comercial y sobrevaluación cambiaria (con su consiguiente impacto sobre las empresas industriales más débiles) y desequilibrios de la balanza de pagos. El segundo fue una consecuencia directa de los procesos de privatización de empresas estatales y privadas (que habían sido previamente nacionalizadas).

Los dos factores actuaron simultáneamente en Chile y ello explica el fortísimo crecimiento de las grandes empresas de ese país ya en los años ' $70^{12}$. Aparentemente, en los demás países estas dos fuerzas dieron lugar a dos oleadas de adquisiciones separadas en el tiempo; la primera (basada en la absorción de empresas privadas) en la segunda mitad de los 70 hasta la crisis de la deuda ${ }^{13}$ y la otra en los ' 90.

\section{III.1.a. La centralización como resultado de las crisis}

La centralización del capital constituye una evolución natural de las crisis en el contexto de la economía de mercado. Y es sabido que los problemas económicos y sociales que tuvieron lugar en América latina desde los años '70 y durante los '80 generaron condiciones propicias para que las empresas de mayor tamaño y, como se intentó mostrar en el apartado II, mejor posicionadas en materia de acceso a fondos, procedieran a la absorción de otras firmas privadas perturbadas por los propios efectos de la crisis o, simplemente, menos favorecidas en términos de acceso al crédito y a la liquidez.

Naturalmente, las diferencias entre empresas con relación al acceso al crédito y la liquidez está determinada por su desigual capacidad tanto para acceder a fondos de terceros

\footnotetext{
12 También en Argentina se realizaron algunas privatizaciones en aquélla década (al mismo tiempo que se disminuían los aranceles, se provocaba una fuerte apreciación de la moneda y se elevaban las tasas de interés) pero fueron muy poco significativas en lo que hace a la magnitud de los activos transferidos.

${ }^{13}$ Se infiere de Ruiz (1997) que esta primera fase se extendió algunos años más en Brasil.
} 
y mantener bajo control su endeudamiento corriente como para evitar que sus ingresos se contraigan al mismo ritmo con que disminuye la demanda en su mercado y en la economía como un todo. $\mathrm{Y}$ es en este último aspecto en que el tamaño (capacidad de acaparar las ventas en el mercado interno) y orientación hacia el mercado externo adquieren una importancia especial.

Pero no se trata sólo de que las coyunturas de crisis abrieron a los ge oportunidades de crecimiento a través de la absorción de empresas privadas más débiles sino que la propia morfología de la crisis y la forma en que fue gestionada por el Estado ofrecían fuentes adicionales de negocios altamente rentables que sólo las grandes empresas se encontraban en condiciones de explotar. De hecho, en los '70 y '80 los ge experimentaron un salto cuantitativo en materia de financierización gracias al acelerado crecimiento de la deuda pública interna. Las modalidades específicas de la actividad especulativa de los ge (tenencia y negociación de activos financieros) fueron modificándose en función de los cambios operados en la coyuntura. El punto a destacar aquí es que, según surge de diversos estudios, su importancia relativa en la cartera global de inversiones de los ge se ha incrementado significativamente desde los ' 80 .

Lo ocurrido en Brasil resulta ilustrativo de todo lo anterior. Asegura Ruiz op cit., que "las grandes empresas mantuvieron su capacidad de acumulación durante la década de 1980 a pesar de la recesión y de la inestabilidad económica. Redujeron su endeudamiento y pasaron a aplicar los recursos ociosos en el mercado financiero y a utilizarlos en la adquisición de activos reales". Fue así como adquirieron empresas competidoras, incorporaron actividades complementarias o subsidiarias respecto de su ámbito de expansión o incluso especularon y adquirieron participaciones en empresas líderes y activos considerados seguros en minería, inmuebles y actividad forestal.

Más aún, la recesión estimuló las estrategias centradas en el control de los mercados. La intención era "construir espacios económicos donde pudiesen ejercer su poder de mercado y defender la rentabilidad de sus activos". Para enfrentar la recesión y aprovechar la subvaluación cambiaria, los grupos buscaron reorientar parcialmente sus negocios hacia las exportaciones.

En suma, el crecimiento de los ge se vio estimulado por los episodios de crisis de los '70 y '80 porque abrió nuevos cauces a destinar su liquidez a la adquisición de otras empresas. Más aún, si se admite que la gravedad de los efectos sociales y económicos de la crisis de la deuda resultó significativamente amplificada por la estatización de los pasivos privados que se practicó en todos los países de América Latina ${ }^{14}$ (al mismo tiempo que se incrementaban las transferencias de recursos fiscales precisamente para promover el crecimiento de los ge) resulta incluso correcto afirmar que las grandes empresas jugaron un papel significativo en la propia génesis de la crisis que tan favorable resultó en materia de oportunidades para su crecimiento.

\footnotetext{
$14 \mathrm{Y}$ por otros aspectos relacionados con la gestión de la deuda externa realizada por los gobiernos de los países deudores como la falta de investigación de operaciones de naturaleza irregular o ilegal, la negativa a negociar con los acreedores a través de un frente de países deudores, etc.
} 
III1.1.b. Oportunidades de expansión creadas por las privatizaciones

Además de reforzar sus posiciones en actividades exportadoras, las grandes empresas de América latina participaron de una nueva oleada de adquisiciones a través de las privatizaciones de empresas estatales, asociadas en general con corporaciones de capital extranjero. Ciertamente, en la medida en que estas adquisiciones fueron afrontadas a través de un aumento del endeudamiento de los ge, su impacto neto sobre su tamaño fue muy inferior a la (muy elevada) magnitud de los activos transferidos. Más aún, muchos ge vendieron sus participaciones en las empresas estatales a sus socios extranjeros (para disminuir con ello sus pasivos) pocos años después de concretadas las operaciones de compra y no utilizaron los fondos obtenidos para expandirse en la actividad industrial. Con todo, las privatizaciones jugaron un papel clave como salvoconducto para lograr incrementos rápidos y económicos de la escala de los ge latinoamericanos en los '80 y '90.

Corresponde incluir también aquí dos procesos de privatización de empresas privadas. El de las compañías que habían sido nacionalizadas durante el gobierno de Allende en Chile, que tuvo lugar a mediados de los '70 y que permitió un salto abrupto en la escala (y en muchos casos el propio nacimiento) de los principales ge de ese país (Sanfuentes, 1984). Y la de la banca privada que había sido nacionalizada luego de la crisis de la deuda en México, realizada en 1990. Como ya se comentó, estas adquisiciones jugaron un papel clave en el crecimiento de los ge mexicanos porque les ofreció una oportunidad única para materializar un salto rápido y económico (en términos del esfuerzo financiero requerido) de tamaño (Garrido, 1998).

III.2. Inversiones en nueva capacidad en sus respectivos países

Como se muestra en el Anexo, la inversión en AL disminuyó bruscamente en los ' 80 y registró una recuperación relativamente débil en los '90. Debe recordarse que la capacidad instalada se encontraba en buena medida ociosa cuando se inició el ciclo de recuperación del nivel de actividad económica en los últimos años de los '80 en algunos países y en los primeros de los ' 90 en otros. Por otra parte, ya en los ' 90 , cada una de las crisis financieras ocurridas desde la mexicana de fines de 1994 provocó una interrupción abrupta del ingreso de capitales y, con ello, una inflexión recesiva del ciclo económico. Así, puede afirmarse que a lo largo de las últimas tres décadas las grandes empresas de América Latina han realizado pocos proyectos de inversión nuevos.

Afirman Garrido y Peres (op.cit.) que no sólo se verificaron niveles muy bajos de inversión en nueva capacidad en el sector manufacturero de América latina en los '90 sino que fue también muy modesta la renovación y modernización del parque de equipos existente $e^{15}$.

\footnotetext{
${ }^{15}$ Como se explicó en el inciso anterior, la necesidad de disminuir los costos en el nuevo escenario de los '90 fue cubierta con estrategias de otro tipo, en que la racionalización y el aumento de la intensidad del trabajo jugaron un importante papel.
} 
Respecto de la orientación de los proyectos de expansión que se efectivizaron sólo cabe aquí confirmar las indicaciones volcadas en el Anexo. Como lo señalan todos los estudios reseñados, en Argentina, Brasil y Chile los ge ampliaron sus inversiones en la actividad agroindustrial y de commodities industriales para la exportación construidas durante los '80, generalmente con significativo apoyo estatal. Por ejemplo en Brasil, según Miranda (1996) los ge que en los '80 se habían volcado a negocios de exportación de commodities profundizaron esta estrategia en los '90. En Chile tuvo lugar una oleada significativa de inversión en nueva capacidad en el período 1989/94, también en commodities industriales para la exportación (Díaz, op.cit.).

En México, desde mediados de los '80 la estrategia de las grandes empresas apuntó a una integración creciente con los EE.UU. que se selló en 1994 con la conformación del Nafta. Y en los '90 las nuevas inversiones se concentraron precisamente en las ramas que, bajo el comando de las corporaciones extranjeras, protagonizaron esta integración (automóviles, electrónica). Dice Garrido (1998) que las inversiones realizadas por las grandes empresas en los '80 en estas ramas apuntó no tanto a la expansión de la capacidad instalada en el país como a la modernización de los equipos y la adquisición de firmas en el exterior.

\section{III.3. Activos y pasivos externos}

\section{III.3.a. Inversión en el exterior}

Chudnovsky y López (1999) han coordinado un estudio sobre la internacionalización de las grandes empresas de Argentina, Brasil, Chile y México de cuyos resultados merecen destacarse aquí los siguientes:

-la inversión directa en el exterior (IED) por parte de corporaciones locales comenzó lentamente en América latina como una tendencia en los años '60 (salvo casos aislados de empresas que se internacionalizaron muy tempranamente) y en los ' 90 se registró un salto cuantitativo. Chile es el país en que este incremento resultó más significativo y Brasil la nación con más baja relación IED/PBI.

-orientación sectorial; las grandes empresas de la región invierten en el exterior en las mismas ramas en que actúan en sus países de origen

-orientación espacial; casi toda la IED realizada se dirige a países vecinos u otros de América Latina.

Según Garrido y Peres (1998) sólo un reducido conjunto de ge latinoamericanos, los más grandes, han realizado inversiones directas en el exterior, casi siempre a través de la adquisición de empresas existentes. La mayor parte de estas inversiones se concentra en otros países de la región, en muchos casos porque son realizadas en el marco de acuerdos oligopólicos entre las corporaciones que lideran los diversos mercados nacionales.

Bonelli (1998) afirma que los grupos brasileños comenzaron a intensificar su internacionalización a fines de los ' 80 y en los '90, estableciendo filiales en el exterior (en general en asociación con firmas del país receptor). Según Garrido (1998), los ge mexicanos experimentaron un primer salto en su grado de internacionalización productiva 
luego de 1983 por medio de un aumento de las exportaciones y otro a partir de 1988 a través de un crecimiento de sus inversiones en los países de destino de sus exportaciones (generalmente, en asociación con empresas extranjeras). Se ha observado desde entonces una drástica intensificación de los vínculos entre los ge y el capital extranjero. La IED de los ge mexicanos se aceleró en la segunda mitad de los '90, aunque sigue estando altamente concentrada en un escaso número de grandes operaciones.

Algunas de las grandes empresas industriales de América Latina le asignan a la IED un papel importante en sus estrategias de actuación en el nuevo escenario instalado desde los '90. El esquema ideal, según se comenta en varios de los estudios reseñados, es el siguiente: el liderazgo que ejercen los ge en el mercado interno debería proporcionar una base estable de funcionamiento, mientras que el mercado externo (abastecido a través de exportaciones cuya penetración se intenta reforzar a través de cierta presencia física en los mercados de destino) debería proveer las oportunidades de expansión.

III.b. Otros pasivos y activos en el exterior

Desde finales de los años '70 y a medida que las economías de la región se sumergían en una sucesión de episodios de crisis, las ge transformaron una parte de su liquidez en activos reales o financieros de refugio en el exterior. Este proceso, junto con la estatización de los pasivos en moneda extranjera contraídos a fines de los ' $70^{16}$, dio lugar a un aumento de los activos externos netos de las grandes empresas y ge de América Latina.

En los años '90, luego de la reconexión de los países de la región con el mercado financiero privado internacional (y en paralelo con una nueva expansión de la oferta de crédito) conseguida a partir del Plan Brady, el endeudamiento externo de las grandes empresas volvió a aumentar, por lo menos en Argentina, Brasil y México. Todo parece indicar que la amplia desinversión efectuada por estas corporaciones desde 1995 de sus negocios industriales y de servicios a favor de las empresas extranjeras debe haber conducido a una nueva fase de expansión de sus activos externos netos.

\section{III.4. Orientación sectorial de la inversión}

Durante las últimas tres décadas se observaron, en varios países, oleadas de conglomeración y también de des-diversificación (en adelante, des-dvr).

En Argentina, Brasil, México y Chile los ge se expandieron significativamente a través de la conglomeración a fines de los '70 y principios de los ' 80 . Mientras que también las privatizaciones (las de los '80 y las de los '90) proporcionaron en general oportunidades de crecimiento conglomerado a las grandes empresas en todos los países.

${ }_{16}$ Por ejemplo, la deuda externa privada bruta de Argentina disminuyó de u\$s 15.600 millones en 1981 a u\$s 4.200 en 1987 para comenzar a crecer nuevamente desde entonces. 
Hubo también fases de des-dvr. Por ejemplo, tras el estallido de la crisis financiera en 1982, la mayoría de los grandes grupos económicos mexicanos atravesaron un proceso de reestructuración y saneamiento que se prolongó hasta 1987 y durante el cual se desprendieron de algunas de las adquisiciones realizadas en el período 1977/82 (Rendón Trejo, 1997).

Según Sanfuentes (1984), en los '80 se puso de manifiesto que los ge chilenos que habían crecido rápidamente desde los '70 habían realizado numerosas inversiones que derivaron en rentabilidades negativas. De hecho, varios de los ge que habían crecido en base al endeudamiento fueron intervenidos o liquidados poco después de la crisis de la deuda.

También en Brasil tuvo lugar un episodio de des-dvr. En un estudio sobre 18 grandes empresas brasileñas se encontró que la mayoría pasó por un proceso de autodepuración que consistió en desprenderse de activos que habían sido adquiridos como reserva de valor (inmuebles, yacimientos mineros e inversiones forestales), des-dvr de actividades industriales (especialmente, luego de la caída de los regímenes respectivos, en las ramas intensivas en tecnología) y, por último, cierre o venta de sus plantas obsoletas (Ruiz; op. cit.).

En Argentina los ge protagonizaron, después de 1995, una oleada de operaciones de venta de activos que habían adquirido en las privatizaciones a sus socios extranjeros.

Así, podría decirse que el material empírico consultado permitiría sustentar la existencia del siguiente patrón. Por un lado, la conglomeración tiende a presentarse en fases de expansión de los ge que, como es sabido, resultó estimulada por las crisis financieras que afectaron al resto de las empresas en sus respectivos países y por las privatizaciones. Por el otro, la des-dvr tiende a imponerse cuando son los propios ge los que protagonizan episodios de reestructuración, crisis o franco retroceso. Esto es lo que ocurrió tras la crisis financiera de 1982 (México y Chile) y, más recientemente, luego del avance masivo de las empresas extranjeras en América latina en la segunda mitad de la década de los '90.

Naturalmente, queda pendiente el análisis y la interpretación de este fenómeno, tarea que será abordada más adelante en el inciso c de la sección IV.1.

En suma, el apartado III reunió información acerca del modo en que los ge latinoamericanos aplicaron sus fondos invertibles en los ' 80 y los '90. Como se comentó, la adquisición de activos existentes constituyó una esfera importante de canalización de fondos mientras que, en lo atinente a nueva capacidad productiva, las grandes empresas orientaron sus inversiones hacia las actividades exportables. Se ha observado también una módica internacionalización del portafolio de inversiones de las empresas. Por último, no parece apropiado evaluar la orientación sectorial de la inversión de los ge tomando el período comprendido por las últimas tres décadas como un todo. La razón es que se observaron movimientos de conglomeración y también de des-dvr. 
A continuación, en el apartado IV se analizarán algunos aspectos cualitativos de este proceso.

\section{LOS OBSTACULOS AL CRECIMIENTO}

En el apartado II se han enumerado y descrito brevemente los principales canales a través de los cuales las grandes empresas de la región pudieron defender o incrementar su acceso a fondos disponibles para la inversión. Mientras que el apartado III se ocupó de explicar cómo se aplicaron esos fondos. Ahora se propone una evaluación más bien cualitativa de este proceso de crecimiento.

De un modo general puede afirmarse que, aunque no escasean las referencias aisladas y laterales, los estudios empíricos carecen de un planteo sistemático acerca de los obstáculos al crecimiento de los ge en América Latina, tanto los de índole económica como los de naturaleza social ${ }^{17}$. Es por ello y también, en buena medida, por la propia naturaleza de estos obstáculos, que su presencia debe ser inferida a través de otros fenómenos. Y es de este modo como, partiendo de la reseña empírica, se puede sugerir la existencia de dos tipos de límite al crecimiento de los ge de la región.

1) Escasez de oportunidades de inversión ante el aumento de la competencia con el capital extranjero. Se analizan tres conjuntos de evidencia empírica que ponen de manifiesto de un modo bastante directo esta escasez.

(a) El desplazamiento de los ge de muchos de sus principales negocios (especialmente en la industria) por parte de las empresas multinacionales.

(b) La caracterización que se presenta en los estudios sobre el perfil actual de producción, exportaciones e inversiones en el exterior de las grandes empresas de capital nacional.

(c) Barreras al crecimiento independiente en sectores dinámicos. Se recopilan aquí evidencias acerca de las dificultades con que tropiezan los ge para crecer en muchas de las actividades de las que aún no fueron del todo desplazados.

2) Límite social.

IV.1. Creciente relación de competencia con el capital extranjero

Aquí se discuten tres cuestiones íntimamente relacionadas entre sí. En primer lugar, el desplazamiento experimentado por las grandes empresas nacionales por parte de las compañías multinacionales. En segundo lugar se ofrece una caracterización cualitativa (es decir; en términos de rentabilidad y expectativas de crecimiento) del patrón de actividades en que están actualmente involucrados los grupos de América latina. Se analiza, por último, un conjunto de estudios referidos al establecimiento de alianzas entre las empresas de la

\footnotetext{
${ }^{17}$ El análisis de Leff sobre las consecuencias derivadas de la creciente concentración económica y del poder de los ge es siempre omitido, aún en ensayos en que se invocan otros tramos de aquellos artículos en que estas ideas fueron publicadas. De la obra de este autor sólo se rescatan (fuera de contexto) aquellas ideas que pueden ser reprocesadas en el contexto de la teoría de la firma. Merhav tuvo menor suerte; carente de ideas originales sobre la teoría de la empresa, su obra ha desaparecido por completo de las referencias bibliográficas sobre el tema.
} 
región y las de los países desarrollados (pd). Se infiere de aquí la existencia de barreras al crecimiento independiente de las corporaciones de AL.

IV.1.a. El avance de las empresas extranjeras

Las grandes empresas de la región se han mostrado incapaces de proseguir con la acumulación en un gran número de actividades industriales y de servicios en que el capital extranjero ha profundizado su penetración en los años '90. Esto se expresa en el peso creciente de éste último en el conjunto de las grandes corporaciones en todos los grandes países de América Latina, en particular después de 1995 en paralelo con la intensificación de los flujos de IED a la región.

Es natural, por lo tanto que, como lo documentan numerosos estudios (por ejemplo, Garrido y Peres, op.cit.), este desplazamiento haya resultado más intenso en los negocios industriales de los ge, especialmente en los más dinámicos y de mayor contenido de valor agregado (y beneficios). Esto ha llevado, incluso, a la desaparición de algunos ge por venta al capital extranjero.

Ciertamente, este retroceso relativo puede no ser definitivo en términos históricos ya que las corporaciones extranjeras manejan sus inversiones internacionales con creciente flexibilidad y pueden replegarse en el futuro de las posiciones recientemente adquiridas en la región ante una coyuntura que consideran adversa. Así, lo que pone de manifiesto la existencia de un límite absoluto a la capacidad del capital nacional para operar en ciertas actividades no es tanto su ausencia efectiva en la rama en cuestión sino el grado en el cual su presencia se encuentra condicionada por las fluctuaciones de la inversión extranjera en el país.

Por tratarse del país de América Latina en que las grandes empresas industriales habían avanzado más firmemente hacia actividades tecnológicamente complejas, el caso de Brasil resulta de particular interés. Un pormenorizado estudio de una muestra de grandes empresas de ese país (Rocha y Kupfer, 2002) afirma que el nuevo escenario de los '90 amplió las asimetrías competitivas entre las empresas nacionales y las extranjeras (en materia de acceso a la tecnología y financiamiento) tornando a las primeras más vulnerables a las adquisiciones por parte de las segundas.

De hecho, se verificó a lo largo de aquella década un acelerado proceso de desnacionalización de empresas en la mayoría de los sectores económicos. Según la investigación citada en el párrafo anterior, las corporaciones multinacionales absorbieron íntegramente los 20 puntos porcentuales en que se contrajo la participación de las empresas estatales más un punto porcentual perdido por las compañías de capital brasileño (p.13). Esto fue resultado de dos procesos combinados:

- una menor participación de las empresas nacionales en la desestatización que tuvo lugar entre 1991 y 1996 y

- un retroceso neto de las nacionales en favor de las multinacionales entre 1996 y 1999

Observando los cambios producidos a lo largo de todo el período 1991/99, surge que: 
- en aquellas ramas en que se produjeron privatizaciones (commodities industriales y servicios), las empresas nacionales sólo consiguieron retener una parte menor de la transferencia de activos estatales ${ }^{18}$. Con todo, estos fueron los únicos sectores en que el capital nacional amplió su participación relativa

- en las restantes actividades (toda la industria, excepto commodities) las empresas de capital nacional experimentaron un notorio retroceso en favor del capital extranjero

Como resultado de estos desplazamientos, la participación de las multinacionales en el panel de las empresas más grandes pasó de 36\% a 53\% de las ventas industriales entre 1991 y 1999 y de $9 \%$ a $26 \%$ en servicios (p 14, tabla 4) ${ }^{19}$.

Rocha y Kupfer lo evalúan del siguiente modo; "las empresas nacionales fueron desplazadas de sus posiciones en la industria hacia los servicios, especialmente los de infraestructura. Ciertamente, el proceso de privatización en este sector se reveló como de gran importancia en la apertura de espacios para acomodar a las empresas nacionales en retirada de la actividad industrial ( $\mathrm{p}$ 15)". Esto es; de no haber tenido lugar las privatizaciones, el retroceso relativo del capital nacional habría sido aún mayor.

Según estos autores la apertura comercial, al situar a muchas empresas de capital nacional en una situación de vulnerabilidad, elevando con ello su predisposición a vender al capital extranjero, fue uno de los factores explicativos de la oleada de IED ocurrida en Brasil en la segunda mitad de los '90. En suma, el avance de las corporaciones multinacionales ha comprimido la participación cuantitativa de las empresas nacionales así como la diversidad de esferas de actividad en las que actúan y en las que pueden invertir para crecer.

Al igual que en Brasil, las inversiones de empresas extranjeras en México se aceleraron en la segunda mitad de los '90. A decir verdad, la IED resultó muy activa desde principios de la década incrementando su peso en la inversión total desde $0,3 \%$ del PBI en $1990 / 93$ a $4,9 \%$ en $1994 / 96$ y a $7,5 \%$ en $1997 / 99$. La contrapartida fue un retroceso relativo de la inversión privada nacional ${ }^{20}$ que en 1997 tuvo un peso en el PBI inferior al de la IED (Garrido, 2001).

El primer salto observado en la penetración de la inversión extranjera en Chile tuvo lugar en 1985/90 en el marco de la segunda fase de privatizaciones encaradas por el gobierno dictatorial. Sumidos aún en un proceso de saneamiento financiero, la mayoría de los ge nativos quedó al margen de estas operaciones, excepto aquellos que habiendo sobrevivido a la crisis financiera de 1981/2, se asociaron con empresas extranjeras. Según Fernández Jilberto (op cit), esta tanda de privatizaciones constituye el punto de partida de la desnacionalización y globalización de la economía chilena. Ya a mediados de los '90, los

18/ Excepto en los servicios de infraestructura, donde la participación de nacionales y extranjeros se dividió en partes iguales.

19/ En este trabajo no se identifica las asociaciones de capital nacional y extranjero. En Goldstein y Schneider (2004, tabla 4) se estima que estas asociaciones aumentaron su participación en las ventas de las 100 empresas no financieras más grandes de 5\% en 1990 a 23\% en 1998, básicamente gracias a su intervención en privatizaciones. En este cálculo las multinacionales "puras" pasaron de $27 \%$ en 1990 a $34 \%$ en 1998.

${ }^{20} \mathrm{Al}$ mismo tiempo que, como se comentó en otro inciso, se incrementaba la exportación de capitales por parte de las empresas y ge más grandes. 
ge compartían la propiedad de sus principales empresas con las corporaciones extranjeras (Castillo et al, 1996) y en la segunda mitad de aquélla década, una nueva oleada de ventas de empresas nacionales al capital extranjero tuvo lugar (Sanfuentes, 2001).

Aparentemente, según Moguillansky y Bielschowsky (op.cit.), las extranjeras habían aumentado su peso entre las 100 empresas industriales privadas más grandes de América latina entre 1990 y 1996. Y esto fue antes que la IED se acelerara, luego de la crisis de México de fines de 1994.

Resumiendo, lo que en las estadísticas sobre la composición de las grandes empresas se presenta como un retroceso relativo del capital nacional (una tendencia de este a acaparar una menor parte de la expansión de las ventas) refleja en realidad su retiro de aquellos negocios en que las corporaciones de los países desarrollados tienen un mayor interés.

IV.1.b. Los actuales negocios de las grandes empresas de América Latina

Se llega así a la siguiente cuestión complementaria: ¿cómo caracterizan los estudios el perfil sectorial de los negocios de los ge latinoamericanos en términos de rentabilidad y perspectivas de crecimiento? Existe un amplio consenso también aquí; como resultado de su desplazamiento por el capital extranjero, las grandes empresas de la región acentuaron su ya característica dedicación a las ramas industriales tradicionales y de producción de commodities industriales (Chudnovsky y López, op.cit.), rubros maduros por definición.

En Brasil, las grandes empresas de capital nacional habían comenzado a actuar en sectores intensivos en tecnología en los '80 con el apoyo del Estado y en el marco de una elevada protección. Cuando esta política se desmontó, a principios de los '90, los ge se replegaron a aquellas actividades en que habían actuado tradicionalmente dejando a las extranjeras con el monopolio de aquellos sectores (Ruiz, op. cit).

Respecto de la actividad exportadora de los ge latinoamericanos, Garrido y Peres (op. cit.) afirman que la mayor parte corresponde a rubros basados en el procesamiento de recursos naturales y se dirigen a otros países de la región. Los ge están ausentes de las ramas intensivas en tecnología y comercialización (diferenciación del producto). Esta marginación se torna más estricta aún en el nuevo escenario porque esas actividades ya no pueden ser explotadas al margen de la competencia mundial. Ciertamente, la penetración de mercados externos permite a las grandes empresas de América Latina superar las barreras a la expansión que plantea una acumulación limitada al mercado doméstico. La dificultad estriba en que, según estos autores, este tipo de negocios enfrenta en el largo plazo perspectivas de agotamiento en sus posibilidades de crecimiento. Al mismo tiempo, sin embargo, el desplazamiento hacia negocios más promisorios se encuentra obstaculizado por el abrumador predominio técnico y financiero de las empresas transnacionales. Estas circunstancias explicarían la fuerte corriente de ventas de empresas de los ge de la región al capital extranjero (69-70). 
Esta es, según Miranda (op.cit.), la situación en que se encuentran los grandes exportadores industriales de Brasil que ven obstruida su progresión hacia mercados más dinámicos y productos complejos. Respecto de México, dice Casar (op.cit.) que las exigencias en materia de competitividad que se derivan del nuevo escenario podrían estar más allá de las posibilidades de las grandes empresas de capital nacional, mientras que las perspectivas de expansión a través de las ventas externas resultan muy limitadas en virtud del bajo dinamismo que caracteriza a los negocios de exportación de los ge.

La misma clase de problemas reaparece en los diagnósticos sobre la reciente desaceleración de la acumulación en Chile. Según Sanfuentes (2001), algunos de los sectores más dinámicos se han agotado como esferas de inversión rentable (cobre y telecomunicaciones) y no han sido reemplazados por otras actividades de relevancia cuantitativa similar. Las causas de esta desaceleración (al margen de la crisis financiera internacional que se inició en 1997 y sus consecuencias) habrían sido las siguientes; progresivo copamiento de los mercados externos hacia donde se dirigen las exportaciones chilenas y fracaso de las empresas para desplazarse hacia actividades más rentables (incluso a lo largo de la misma cadena de producto) pero que requieren la incorporación de tecnología moderna, precisamente aquello en que su atraso resulta más notorio.

En el estudio reciente de Moguillansky y Bielschowsky (op.cit.) confirma y enriquece este diagnóstico. La economía chilena se encontraría en la segunda mitad de los '90 frente a la "culminación de un ciclo". Para despejar las dudas que plantea el empleo un tanto equívoco del término "ciclo" conviene mencionar que, en un apartado posterior, el mismo informe entiende que existen en Chile factores que amenazan el crecimiento sostenido de la inversión industrial, como su elevada concentración en un grupo muy reducido de ramas. Las razones serían: la existencia de retornos decrecientes en ciertas actividades, la disminución de los subsidios, la caída de los precios internacionales de productos de exportación importantes, la apreciación de la moneda doméstica, la creciente competencia y la rentabilidad decreciente. En suma: la continuidad de la acumulación se encuentra condicionada por la caída de la rentabilidad y las escasas perspectivas de expansión que prometen los rubros en que las empresas están actuando.

Como ocurrió también en México, las grandes empresas chilenas reaccionaron a este escenario adverso buscando ganancias en el exterior (participando, por ejemplo, en las privatizaciones de empresas públicas en Argentina). Pero esta ruta encontró sus propios límites; las inversiones chilenas en el exterior ya habían mostrado muy bajos niveles de rentabilidad entre 1994 y 1997 pero en 1998 y 1999 las ganancias descendieron aún más hasta alcanzar niveles negativos. Se concluye entonces que "montos considerables de recursos nacionales se invirtieron con bajísima rentabilidad" (Sanfuentes, 2001).

En suma, las grandes firmas latinoamericanas de capital nacional se encuentran confinadas en actividades económicas escasamente rentables y carentes de perspectivas de expansión. En Argentina, Brasil, Chile y México las firmas de capital nacional están en retirada de los sectores intensivos en conocimiento (Chudnovsky y López, op.cit.) en que su presencia, fuertemente apoyada por el Estado, ya era de por sí muy limitada. 
Ciertamente, para evitar ser absorbidas, algunas de las grandes empresas de la región se ven impulsadas a acelerar su propia expansión a través de la adquisición de otras compañías, primero en sus países y luego en el resto de la región. De hecho, algunos de los estudios disponibles sobre la internacionalización de los ge latinoamericanos dejan entrever la idea de que esta constituye más un reflejo de las dificultades que enfrentan para proseguir con la acumulación en sus respectivos países que un síntoma de vitalidad y capacidad de crecimiento.

En una reseña sobre el comportamiento de los ge de América Latina durante los '90 realizada por Mendes de Paula (2003) se afirma que el principal móvil de la IED realizada por estas corporaciones es la búsqueda de oportunidades de inversión, esto es, la ampliación de las "perspectivas de crecimiento" (p 32). Así, con escasas posibilidades de inserción en actividades más dinámicas, las grandes empresas de América latina buscan expandirse a través de la dvr espacial, casi siempre en países limítrofes o, a lo sumo, de la región. Los intentos de radicación de inversiones en los países desarrollados han culminado, en general, en el fracaso.

Bonelli (op.cit.) afirma que los grupos brasileños comenzaron a intensificar su internacionalización a fines de 10 ' 80 y en los '90 como complemento de su actividad exportadora. "Esto refleja la necesidad de consolidar una salida para el potencial de crecimiento de la empresa. La inversión directa en el exterior pasa a asumir un papel de sustituto de la inversión en el país" (p 236). Asimismo, Garrido (2001) asegura que el principal objetivo de la IED de los ge mexicanos es la búsqueda de esferas de mercado, esto es; un intento por apuntalar, a través de esta presencia, la demanda externa de las empresas.

En el ya citado estudio de Chudnovsky y López en que se ofrece una reseña sobre la IED de las grandes empresas latinoamericanas se presenta un argumento similar al sostenido por Garrido y Peres; el aumento de la competencia en sus mercados domésticos es uno de los factores que impulsa la expansión internacional de los ge más grandes. Para muchas empresas la internacionalización aparece como una necesidad para la supervivencia ya que "cada vez más firmas de la región enfrentarán el dilema de "comprar o ser compradas' (p 57-58)". Según se desprende de los estudios de casos realizados en Argentina, Brasil, Chile y México la mayoría de la IED de firmas latinoamericanas realizada en los '90 tuvo como objetivo la búsqueda de mercados.

Así, la internacionalización se presenta como la forma obligada de expansión de las grandes empresas de la región en una coyuntura en que los mercados domésticos (de por sí limitados y sujetos a fuertes oscilaciones) son crecientemente disputados por las corporaciones multinacionales. En este sentido, resulta opinable la afirmación de Chudnovsky y López de que la internacionalización permite a las empresas proseguir su expansión en lugar de profundizar su diversificación hacia actividades no relacionadas en sus países de origen. A decir verdad, la internacionalización y conglomeración sólo podrían presentarse como alternativas en un mismo momento si el contexto resultara en general favorable a la expansión de los ge. La inversión sólo se vuelve conglomerada cuando expresa la necesidad de la empresa de crecer más rápidamente de lo que lo hace su actividad principal y su incapacidad para hacerlo por medio de proyectos de dvr relacionada. Pero lo que se ha observado recientemente es un fenómeno distinto; algunas de 
las grandes empresas (las más grandes) se internacionalizan a la vez que detienen su expansión o se contraen (vía des-dvr) en sus países de origen. Algo más sobre esta cuestión se propone en el siguiente acápite.

En suma, los ge han sido crecientemente confinados a actividades económicas escasamente rentables y dinámicas que no proveen tampoco oportunidades de expansión basadas en el comercio internacional. Ciertamente, en los '90, la internacionalización ha abierto un cauce de inversión a alguno de los ge más grandes de la región, al mismo tiempo que se aceleraba la entrada de empresas extranjeras en América Latina. Con todo, en la medida en que reposa sobre el mismo tipo de negocios y se despliega a lo largo de un espacio económico restringido y de crecimiento inestable, la internacionalización abre un proceso de centralización regional que parece incapaz, por sí mismo, de ensanchar significativamente las perspectivas de expansión de los ge latinoamericanos.

\section{IV.1.c. Barreras al crecimiento independiente}

En muchas de las actividades de las que no han sido desplazados todavía, los ge domésticos enfrentan dificultades para proseguir su expansión manteniendo el control absoluto de sus empresas. Estos obstáculos se presentan en general bajo la forma de deficiencias competitivas en áreas corporativas específicas cuya superación pone a las grandes empresas de la región frente a la necesidad de establecer alianzas o asociaciones con grandes corporaciones multinacionales. Y existen sectores en que la propia supervivencia de los ge locales se debe a su predisposición para el establecimiento de acuerdos de este tipo (Chudnovsky y López, op cit). Es por ello que el estudio de (i) los objetivos y (ii) los resultados y límites de estas asociaciones proporciona una perspectiva adicional para el análisis de los obstáculos al crecimiento que encuentran las grandes empresas de la región.

\section{IV.1.c. i. Objetivos de las alianzas}

Las alianzas se han incrementado en todo el mundo en los '90 como un instrumento que contribuye al posicionamiento de las grandes empresas frente a las acciones de los rivales, a la evolución del mercado y a otros acontecimientos. Es también un fenómeno ampliamente difundido entre las grandes empresas de América Latina.

Las alianzas estratégicas y joint ventures constituyen una vía por la cual las grandes empresas de AL han intentado sortear los límites que enfrentan al crecimiento sin perder el control sobre su capital (a diferencia de las asociaciones con inversores externos y las fusiones $^{21}$ ). El impulso para la concreción de alianzas por parte de empresas de América

\footnotetext{
21 En las alianzas estratégicas suele acordarse el intercambio cruzado de acciones (en general inferiores al $15 \%$ del capital) al solo efecto de establecer un compromiso de las partes respecto del cumplimiento de los objetivos del acuerdo. En el caso de los joint ventures, los socios participan del capital de un emprendimiento conjunto, legalmente independiente respecto de las empresas asociadas.
} 
Latina provino del aumento de la competencia derivada de la apertura comercial y del crecimiento de IED hacia la región.

En una reseña reciente sobre el comportamiento de los ge de América Latina (Kotabe y otros, 2000) se ofrece un panorama de las principales motivaciones que impulsan a las grandes empresas de la región a involucrarse en alianzas estratégicas con corporaciones extranjeras y de allí se infiere que estas asociaciones constituyen un intento por superar sus insuficiencias en las siguientes dimensiones básicas del crecimiento;

- los recursos críticos en que reposa su capacidad de apropiación de beneficios extraordinarios (capacidad tecnológica, estructura y capacidad de comercialización y recursos financieros)

- acceso a mercados

- aumentar el control sobre las condiciones de competencia. Esto puede adoptar dos formas: asociarse para bloquear, conjuntamente, el acceso al mercado por parte de terceras empresas o asociarse con (para no ser desplazado por) un rival de mayor tamaño y competitividad

Así, las alianzas se presentan en su doble carácter de canal para superar la insuficiencia propia en materia de capacidad de expansión y, a la vez, de resguardo frente al aumento de la competencia. Una evidencia de lo primero es que, en la mayoría de los casos, el crecimiento a través de la internacionalización de las corporaciones de mayor tamaño de América Latina es acompañado por el establecimiento de alianzas con corporaciones extranjeras conduciendo, con ello, a la apertura del capital a las empresas extranjeras (Garrido, 2001 sobre México; Quadros y Carvalho, op. cit., sobre Brasil). Se trata de un paso que los ge de la región (históricamente tan celosos del control sobre el capital de sus empresas) han debido dar con el objeto de acceder a la tecnología y los recursos financieros requeridos para la expansión. El segundo aspecto resulta aún más evidente; ante el ingreso masivo del capital extranjero a las ramas más dinámicas los ge debieron formar alianzas, para no ser totalmente desplazados (Casar, op.cit, sobre México).

En suma, la amplia difusión de las alianzas pone de manifiesto las dificultades que enfrentan las grandes empresas de la región para sostenerse o crecer en el nuevo escenario. El contenido de estas asociaciones (acceso a tecnología, financiamiento, etc.), por su parte, permite situar de un modo preciso las esferas corporativas en que las asimetrías competitivas respecto de las corporaciones extranjeras resultan más notorias y, al menos en el corto plazo, insalvables.

\section{IV.1.c. ii. Resultados y límites de las alianzas}

Tal vez pueda decirse que el resultado más interesante de todos los que se presentan en la ya citada investigación de Kotabe y otros (op.cit.) sea el siguiente. Se preguntó a las empresas qué aspectos eran los más importantes para evaluar el desempeño de las alianzas que habían establecido con compañías extranjeras. De donde surgieron los factores ya comentados, esto es, las "motivaciones" de las alianzas, desde el punto de vista de las empresas de la región. Luego, se pidió a los mismos gerentes que realizaran una evaluación 
de las alianzas. Pero esta evaluación arrojó un resultado paradójico; las peores calificaciones correspondieron, precisamente, a los ítems que acaparan el interés de las grandes empresas de la región para involucrarse en asociaciones con el capital extranjero ( $\mathrm{p}$ 127). Los autores interpretan este resultado como un síntoma de la resistencia de las corporaciones extranjeras a cumplir cabalmente con los objetivos enunciados de las alianzas, en particular el de transferir o compartir aquellos recursos en que descansa, precisamente, su predominio competitivo.

Mendes de Paula (op. cit.), quien se interesó también por este resultado, lo interpreta como una manifestación no sólo de la "tensión inherente a las acciones de colaboración entre empresas" sino, más importante aún, como una pista clave para comprender la elevada tasa de fracasos que presentan las alianzas ${ }^{22}$. En efecto, no se han encontrado investigaciones en que se presente a las asociaciones estratégicas con las empresas transnacionales como un instrumento que haya conseguido remover, de un modo general, los factores que limitan las posibilidades de expansión de las grandes empresas de la región. Lo más frecuente son las evaluaciones desfavorables, como la que surge de una investigación sobre México, donde se concluye que "en contados casos esas alianzas permiten a los grupos mexicanos expandir sus operaciones a los mercados mundiales, ya sea facilitando las exportaciones o en actividades que agregan valor" (Salas-Porras, 1998; 149).

Más aún, lejos de proporcionar un resguardo frente a la absorción por parte del capital extranjero, las alianzas se han mostrado como una de las formas adoptadas para adquirir paulatinamente una participación mayoritaria o total del socio nacional (Chudnovsky y López, op.cit.). Mendes de Paula (op.cit.) afirma que las asociaciones constituyen un fenómeno que aquellos ge que pretenden superar los límites a su crecimiento se ven obligados a abordar a sabiendas de que, al final del camino, pueden perder su independencia. Según este autor, hay dos cuestiones interrelacionadas que emergen de un modo recurrente en la literatura sobre alianzas:

- la asimetría en lo atinente al poder de negociación entre las partes involucradas; en varias experiencias la sociedad constituye un mecanismo empleado por la corporación extranjera para facilitar su ingreso al mercado de la región; pero el socio local (una firma "grande" pero de mucho menor tamaño) termina siendo adquirido,

- su carácter inestable, esto es, su corta duración y tendencia a la ruptura.

En suma, las alianzas no sólo no parecen haber proporcionado una vía para superar los límites al crecimiento de los ge sino que han fracasado incluso en su objetivo de preservar el control sobre el capital. En este sentido, puede decirse que las evidencias sobre la existencia de barreras al crecimiento independiente de los ge latinoamericanos constituyen a veces un síntoma temprano de su futuro desplazamiento total.

${ }^{22}$ Mendes de Paula menciona una tasa de fracasos del 70\%. 


\section{IV.2. Los límites sociales}

En los '70 y '80, años de crecimiento para muchos de los ge latinoamericanos, varios fenómenos ponían de manifiesto la existencia de una situación de escasez relativa de oportunidades de inversión en la actividad productiva; su tendencia a crecer a través de la centralización y a adquirir activos financieros y de refugio, etc. y, por supuesto, la bajísima tasa agregada de acumulación de capital. Este panorama a nivel de las empresas más grandes, combinado con la negativa evolución de la situación macroeconómica, explica el agudo deterioro de los salarios reales y las condiciones de vida de la mayoría de la población de la región en los '80. Más aún, como las restricciones macroeconómicas surgieron en buena medida como consecuencia del salvataje y promoción de las grandes empresas con recursos fiscales, puede afirmarse que el retroceso socio-económico constituye también un resultado del cambio en las condiciones de crecimiento de estas organizaciones.

A su turno, la etapa económica y social abierta con las llamadas "reformas estructurales" vino de la mano de un aumento en la intensidad de la competencia de mercancías y capitales que debieron enfrentar las grandes empresas de la región y, por ende, de una nueva contracción del conjunto de oportunidades de inversión a su disposición. Es cierto que estas mismas reformas proporcionaban otras ventajas y canales de expansión pero resultó claro desde que se inició su implementación que los conglomerados locales iban a verse forzados a operar un proceso rápido de reestructuración de sus procesos productivos y de su cartera de negocios. Esta adaptación adquirió la forma de racionalización, desverticalización con tercerización, sustitución de producción doméstica por extranjera, internacionalización, venta de activos (seguida, al menos en el caso argentino, de fuga de capitales), etc.

Estas estrategias contribuyeron a agravar la tendencia al deterioro de la situación laboral y social sin que la inversión se haya visto revitalizada al punto de ofrecer algún contrapeso. La propia política estatal, al plantearse el objetivo de colaborar con el proceso de ajuste, propició en lugar de compensar, estos procesos. Mientras tanto, las privatizaciones agravaron el panorama social en lo atinente al grado de cobertura previsional, sanitaria y educativa, etc. Se abrieron, por último, nuevas fisuras en el ya deteriorado sistema de representación política en varios de los principales países de la región.

En suma, el período de expansión de los ge latinoamericanos identificado con los años '70 y ' 80 instaló una situación de escasez relativa de oportunidades de inversión que se vio agudizada en los '90. Pese a que las privatizaciones proporcionaron un canal de expansión significativo en los primeros años de dicha década, la presión de la competencia ejercida por el capital y las mercancías del exterior obligaron a los conglomerados a un amplio proceso de ajuste y/o retirada. Durante todo este extenso período la situación social y económica tendió a deteriorarse, primero por la depresión, luego por el proceso de adaptación de las empresas al nuevo escenario. Difícilmente pueda negarse que la persistencia de esta tendencia constituye uno de los límites más claros a la acumulación 
porque erigen un interrogante sobre la viabilidad social y política de las actuales condiciones de crecimiento.

\section{CONCLUSIONES}

En este apartado final se recogen los conceptos más destacados sobre el crecimiento de las grandes empresas latinoamericanas desde los '70 en cada una de las tres esferas en que este proceso fue desglosado aquí.

\section{Acceso a fondos para la inversión}

En el origen del crecimiento observado por las grandes empresas de la región desde los '70 se observa un salto abrupto en su capacidad de captación de fondos disponibles para la inversión.

Los principales canales a través de los cuales estos recursos fluyeron hacia los ge fueron los siguientes:

- un mayor acceso al crédito interno y externo

- transferencias de recursos fiscales

- mayores márgenes de beneficio

- el propio aumento de la escala

\section{Oportunidades de crecimiento}

Respecto de las características que adoptó el crecimiento de los ge de la región, se destacan las siguientes;

- predominio de la centralización respecto de la creación de nueva capacidad

- internacionalización de la producción y de la inversión

- conglomeración en las fases en que el acceso a fondos invertibles excedió a las oportunidades de inversión rentable en el país para los ge y des-dvr cuando estas organizaciones debieron atravesar procesos de reestructuración o retroceso

En el inciso III.4. que trata sobre la orientación sectorial del crecimiento de los ge se ha sugerido la existencia de una relación entre el signo y el perfil sectorial del crecimiento; las fases de expansión serían también de conglomeración, mientras que las de reestructuración, crisis o retroceso serían de des-dvr sectorial.

La internacionalización, en cambio, no encaja tan cómodamente en esta correspondencia. Así, en algunos países (Argentina y Brasil) la exportación de capitales tuvo lugar en los '80, en un período de expansión de los ge, como una expresión de la desproporción existente entre su capacidad de acumulación y las limitadas oportunidades de inversión rentable en sus países. Pero otra oleada se produjo en los '90, en un contexto 
que podría ser caracterizado como de disminución de las oportunidades de expansión de los ge en sus países por el ingreso masivo de empresas extranjeras. En definitiva, la internacionalización parece encontrarse fuertemente condicionada por el balance entre la capacidad de acumulación de los ge y la amplitud de las oportunidades de expansión rentable en sus países y que, por consiguiente, se intensifica tanto cuando se incrementa la primera como cuando se contrae la segunda.

Como se comentó en el mismo inciso, se observaron dos grandes movimientos de des-dvr en las últimas tres décadas en América Latina; el que protagonizaron los ge mexicanos y chilenos altamente endeudados con el exterior en los ' 80 y el que afectó a la mayoría de los grandes conglomerados de la región en la segunda mitad de los '90 como resultado de la irrupción masiva de las empresas multinacionales a estos países.

Una interpretación muy difundida de este último proceso es que el nuevo escenario de intensificación de la competencia indujo a los ge a aumentar su especialización (por ejemplo, Goldstein y Shneider, op.cit.). Pero cabría realizar dos objeciones al uso de la noción de "especialización" en este contexto.

En primer lugar, la sugerencia implícita de que la des-dvr fue "adoptada" como "opción estratégica" presupone la existencia de una gama de alternativas, incluyendo el mantenimiento del status quo. Pero estos escenarios alternativos no son nunca identificados y menos aún analizados en los trabajos empíricos. Más aún, podría decirse que el mantenimiento del status quo habría sido una opción deseable para muchos grupos latinoamericanos que debieron contraer significativamente sus negocios industriales; ¿por qué no los preservaron?

En segundo lugar, porque sugiere la idea de que existen ciertas actividades (precisamente aquellas en que han tendido a concentrar sus recursos) en cuya producción los ge gozarían de ventajas competitivas. Por ejemplo, en un estudio ya citado aquí, Ruiz interpreta la autodepuración practicada por algunas grandes empresas brasileñas a principios de los '90 como movimientos orientados a la "especialización", "hacia sectores en que (...) creían tener ventajas competitivas" (180). También en Chudnovsky y López (op cit), donde se estudió una amplia muestra de grandes empresas de Argentina, Brasil, Chile y México, se afirma que la internacionalización permite a estas organizaciones proseguir su expansión "explotando más a fondo sus activos estratégicos", en lugar de seguir creciendo a través de la dvr no relacionada en sus respectivos países.

En el citado ensayo de Chudnovsky y López se enumeran lo que constituirían ventajas de las firmas internacionalizadas de América latina ${ }^{23}$ y que aparentemente habrían sido identificadas y reveladas por los propios gerentes. Pero la mayoría de estas cualidades resultan tan genéricas e imprecisas que cuesta concebirlas como pilares de un proceso de internacionalización. Más aún, este análisis no ofrece ninguna ponderación de la significación económica efectiva de estas "ventajas" como determinantes de la actual

23/ Las presuntas ventajas serían: capacidades de management, dominio de tecnologías de proceso difundidas, gestiones de producción y calidad eficientes, acceso a financiamiento o habilidades en comercialización y distribución. A lo que se agrega, aunque según los autores sólo en ciertos casos, "capacidad para funcionar en ambientes culturalmente próximos". 
participación de mercado de las firmas o de su capacidad de expansión absoluta o relativa. En el capítulo VI de la tesis se avanza algo más sobre esta discusión, aplicada al caso argentino.

Pero al mismo tiempo que algunas grandes empresas de la región invierten en países limítrofes las corporaciones europeas y estadounidenses han desplazado a las de capital nacional de numerosas actividades industriales ¿Cómo armonizar la presunta "opción estratégica por la especialización" con el material recogido en los incisos anteriores sobre los obstáculos que enfrentan los ge para prosperar y, en muchas actividades, incluso para subsistir? A decir verdad, predominan los testimonios sobre la significativa reducción de los espacios económicos en que los ge pueden competir y sobre las escasas rentabilidad y perspectivas de crecimiento de aquellos en que tienden a quedar confinados.

En otras palabras, la reciente des-dvr de algunos ge latinoamericanos difícilmente pueda ser interpretada como una señal de re-especialización, aunque más no sea por el hecho de que no ha resultado neutral respecto de la magnitud y "calidad" (rentabilidad y perspectivas de crecimiento) de los activos que han conservado en la industria en sus países. A la luz del material empírico analizado, parece razonable interpretar este fenómeno como un síntoma de su retroceso relativo respecto de las corporaciones multinacionales, como la forma específica que adoptó la contracción de la masa de activos productivos en poder de estas organizaciones.

\section{Límites al crecimiento}

Se han señalado aquí dos tipos de límite. El primero se vincula con la escasez relativa de oportunidades de expansión de las grandes empresas de la región en un contexto de intensa competencia internacional.

Algunas de las características de este proceso permiten inferir la existencia de condicionamientos a la acumulación. El crecimiento de la gran empresa moderna se encuentra asociado, como se observó en el capítulo uno, con la capacidad para ir desplazando los fondos disponibles para la inversión desde las actividades menos dinámicas y rentables a las de más acelerado crecimiento y perspectivas. Por su parte, esta capacidad reposa sobre las ventajas con que cuenta para operar en actividades protegidas por barreras a la entrada y, eventualmente, para crear negocios con estas características. El análisis que se presenta en este capítulo pone de manifiesto cómo, la inferioridad tecnológica, comercial y financiera de los ge de América Latina respecto de las empresas de los pd condujo al truncamiento de esta secuencia. Esto es lo que sugieren las siguientes evidencias:

- las grandes empresas de América Latina han tendido a ser desplazadas recientemente de numerosas actividades industriales por parte de corporaciones multinacionales

- los rubros en que se han mantenido se caracterizan por su baja rentabilidad y escasas perspectivas de expansión

-l as más grandes han tendido a exportar a otros países de la región el capital que no podían invertir redituablemente en sus países pero, por el momento, esto no se ha traducido en una ampliación sustancial de sus horizontes de inversión 
- en aquellas actividades dinámicas en que han logrado mantenerse, resulta ostensible su desventaja en materia de tecnología, capacidad de comercialización y financiera; por lo tanto, también parecen carecer de expectativas de expansión allí

- han recurrido a alianzas con grandes corporaciones pero estas no se han mostrado como un medio efectivo para acortar las desventajas antes mencionadas ni, por ende, para ensanchar de un modo duradero las oportunidades de expansión rentable

El segundo límite surge de la tensión que las condiciones de crecimiento imperantes imponen sobre la situación social y política.

Se puede hacer, por último, una presentación alternativa del crecimiento de los ge de América Latina en las últimas tres décadas que dé cuenta de la cronología de los sucesos. Cabría referirse, desde esta perspectiva, a dos etapas bien diferenciadas.

En la primera, los ge experimentaron un incremento en el caudal de fondos a su disposición que desbordó sus oportunidades de inversión rentable en los rubros en que ya actuaban en sus respectivos países y que condujo a una expansión de la masa de activos bajo su control. Este crecimiento se basó, en gran medida, en la adquisición de activos existentes privados y estatales e incluyó un cierto aumento de la internacionalización de la actividad de los ge. Más aún, podría afirmarse que la disponibilidad de fondos excedió las oportunidades de inversión en activos productivos lo que implicó una creciente financierización de las grandes empresas. Nuevas oportunidades de expansión se presentaron en los '90 con las privatizaciones cuya contrapartida, en términos de los fondos requeridos, ha sido una cierta repatriación de activos externos y el renovado acceso al crédito internacional.

En el segundo período, en especial desde 1995, los ge tendieron a verse desplazados de numerosas actividades industriales y de servicios por el capital extranjero. Esto, a su vez, puede haber erosionado su acceso a los fondos, además de haber reducido sus oportunidades de inversión rentable en sus países de origen. En esta fase tuvo lugar una nueva oleada de internacionalización, pero ahora como reflejo de la compresión experimentada en sus oportunidades rentables de inversión en sus países de origen.

\section{REFERENCIAS BIBLIOGRAFICAS}

Bielschowsky, R. y Stumpo, G., (1996), “Cuatro estilos de reestructuración en el sector de empresas transnacionales., Los casos de Argentina, Brasil, Chile y México tras la sustitución de importaciones", En Katz J. (ed.), Estabilización Macroeconómica, Reforma Estructural y Comportamiento Industrial. Estructura y Funcionamiento del Sector Manufacturero Latinoamericano en los Años 90, CEPAL/IDRC-Alianza Editorial, Buenos Aires.

Bisang, R, Bonvecchi, C, Kosacoff, B y Ramos, A., (1996), "La transformación industrial en los noventa: un proceso con final abierto", CEPAL, Oficina en Bs. As. Documento de Trabajo $N^{\circ} 68$.

Bonelli, R. (1998), "Las estrategias de los grandes grupos económicos brasileños", En Peres W. (coord.), Grandes Empresas y Grupos Industriales Latinoamericanos, 
Expansión y Desafíos en la era de la Apertura y la Globalización, Siglo Veintiuno Editores, México y Madrid.

Casar, J. (1996), "Un balance de la transformación industrial en México", En Katz J. (ed.); Estabilización Macroeconómica, Reforma Estructural y Comportamiento Industrial. Estructura y Funcionamiento del Sector Manufacturero Latinoamericano en los Años 90. CEPAL/IDRC-Alianza Editorial, Buenos Aires.

Castillo, M, Dini, M y Maggi, C., (1996), "Reorganización industrial y estrategias competitivas en Chile", En Katz, J. (ed.), Estabilización Macroeconómica, Reforma Estructural y Comportamiento Industrial. Estructura y Funcionamiento del Sector Manufacturero Latinoamericano en los Años 90, CEPAL/IDRC-Alianza Editorial, Buenos Aires.

CEPAL, (2004), Balance Preliminar de las Economías de América Latina y el Caribe, Santiago.

Chandler, A., (1982), "The M-form: industrial groups, american style", European Economic Review, Vol. 19, № 1.

Chudnovsky, D. y López, A., (1999), "Las empresas multinacionales de América latina. Características, evolución y perspectivas”, Boletín Informativo Techint $N^{o} 297$.

Díaz, A. (1996), "Chile: la industria en la segunda fase exportadora, Trayectoria histórica y desafíos para los noventa”, En Katz, J. (ed.); Estabilización Macroeconómica, Reforma Estructural y Comportamiento Industrial. Estructura y Funcionamiento del Sector Manufacturero Latinoamericano en los Años 90, CEPAL/IDRC-Alianza Editorial, Buenos Aires.

Fernández Gilberto, A., (2004), "Neoliberal restructuring, The origin and formation of economic groups in Chile", Journal of Developing Societies, Vol. 20, No 3-4.

Garrido, C., (1998), "El liderazgo de las grandes empresas industriales mexicanas". En Peres W.; Grandes Empresas y Grupos Industriales Latinoamericanos. Expansión y Desafios en la era de la Apertura y la Globalización. Siglo Veintiuno Editores, México y Madrid.

Garrido, C., (2001), "Fusiones y adquisiciones transfronterizas en México durante los años noventa", CEPAL, Serie Desarrollo Productivo, No 111, Santiago.

Garrido C. y Peres, W., (1998), "Las grandes empresas y grupos industriales latinoamericanos en los '90", En Peres, W., (coord.), Grandes Empresas y Grupos Industriales Latinoamericanos, Expansión y Desafios en la era de la Apertura y la Globalización, Siglo Veintiuno Editores, México y Madrid.

Gaughan, P., (1999), Mergers, Acquisitions and Corporate Restructurings, Segunda edición, John Wiley \& Sons Inc, Nueva York, Chichester, Weinheim, Brisbane, Singapur y Toronto.

Goldstein, A. y Schneider, B., (2004), "Big business in Brazil: states and markets in the corporate reorganization of the 1990s", En Amann E. y Chang H. (eds); Brazil and Korea: Economic Crises and Restructuring, Institute for Latin American Studies, Universidad de Londres.

Kotabe, M., Aulakh, P., Santillán-Salgado, R., Teegen, H., Coutinho de Arruda, M. y Greene, W. (2000), "Strategic alliances in emerging Latin America; a view from Brazilian, Chilean, and Mexican companies", Journal of World Business, Vol 35, N 2. 
Mendes de Paula, G. (2003), "Estrategias corporativas e de internacionalizacao de grandes empresas na América Latina", CEPAL, Serie Desarrollo Productivo, $N^{o} 137$, Santiago.

Miranda, J., (1996), "Reestructuración industrial en un contexto de inestabilidad macroeconómica. El caso de Brasil”, En Katz, J. (ed.), Estabilización Macroeconómica, Reforma Estructural y Comportamiento Industrial. Estructura y Funcionamiento del Sector Manufacturero Latinoamericano en los Años 90, CEPAL/IDRC - Alianza Editorial, Buenos Aires

Moguillansky, G. y Bielschowsky, R. (2001), Investment and Economic Reform in Latin America, CEPAL, Santiago, Chile.

Quadros Carvalho, R. y Bernardes, R. (1998), "Cambiando con la economía: la dinámica de empresas líderes en Brasil”, En Peres, W. (coord.), Grandes Empresas y Grupos Industriales Latinoamericanos, Expansión y Desafios en la era de la Apertura y la Globalización, Siglo Veintiuno Editores, México y Madrid.

Rendón Trejo, A., (1997), "Grupos económicos en la década de los ochenta", Economía, Teoría y Práctica, Nueva Epoca, № 8, Universidad Autónoma Metropolitana de México.

Rocha, F. y Kupfer, D., (2002), "Evolucao das empresas líderes brasileiras na década de 90”, Universidad Federal de Rio de Janeiro, Instituto de Economía, Grupo Industria e Competitividade, Disponible en http://www.ie.ufrj.br/gic.

Ruiz, R., (1997); "Reestructuración de los grupos industriales brasileños entre 1980-1993", Revista de la CEPAL $N^{\circ}$ 61, Santiago.

Rumelt, R., (1974), Strategy, Structure and Economic Performance. Harvard Business School Press, Boston, Massachusetts. Edición de 1986.

Salas-Porras, A. (1998), "Estrategia de las empresas mexicanas en sus procesos de internacionalización". Revista de la Cepal, № 65.

Sanfuentes, A., (1984), "Los grupos económicos: control y políticas”, Colección Estudios CIEPLAN N ${ }^{\circ} 15$, Estudio No 98 , Santiago.

Sanfuentes, A., (2001), “Se agotó ‘el modelo’?”, Asuntos Públicos, Informe № 416, Santiago, Disponible en www.asuntospublicos.org.

UNCTAD, (2000), "Cross-border Mergers and Acquisitions and Development", World Investment Report, Nueva York y Ginebra.

UNCTAD, (2003), "Capital Accumulation, Growth And Structural Change". Trade and Development Report. Nueva York y Ginebra.

UNCTAD, (2004), “The Shift Towards Services", World Investment Report, Nueva York y Ginebra. 


\section{ANEXO}

La inversión en América Latina desde los ‘80

El período iniciado en los '70 ha sido considerado como parte de una nueva etapa en muchos aspectos de la evolución económica y social de los países de América latina. Uno de los rasgos que permite considerarlo de este modo es que durante este período se materializa un intenso proceso de cambio en el nivel y composición del capital social. En otras palabras:

- una parte de este capital resultó destruido,

- el resto comenzó a ser explotado en un nuevo contexto social y económico (en términos de propiedad, condiciones de mercado, relaciones entre capital y trabajo y entre empresas) - y, por último, un proceso de nueva acumulación tuvo lugar.

Aquí se abordarán sólo los últimos dos aspectos de este proceso y se lo hará de un modo bastante general, con el único objeto de proporcionar una introducción y marco para la lectura de este capítulo.

1. Evolución de la inversión total

Cuadro 1: Tasas de inversión de los países de América Latina desde la década del '70

\begin{tabular}{lrrrrrr}
\hline & \multicolumn{7}{c}{ Tasa de inversión bruta $1970 / 2000(\%$ del PBI) } \\
\hline Argentina & $1970 / 75$ & $1975 / 80$ & $1980 / 85$ & $1985 / 90$ & $1990 / 95$ & $1995 / 00$ \\
Brasil & 22,3 & 24,0 & 19,4 & 15,9 & 16,9 & 18,8 \\
Chile & 28,9 & 30,3 & 24,0 & 21,8 & 19,5 & 20,5 \\
Colombia & 17,1 & 14,8 & 15,0 & 16,1 & 20,4 & 23,4 \\
México & 18,4 & 17,9 & 19,4 & 17,6 & 18,5 & 18,3 \\
América latina & 21,9 & 22,9 & 21,4 & 17,6 & 19,8 & 20,1 \\
\hline Fuente: UNCTAD (2003, 67, tabla 4.1). & 26,0 & 21,7 & 19,1 & 19,0 & 20,0 \\
\hline
\end{tabular}

La tasa de acumulación experimentó en la mayoría de los países una abrupta caída en los '80 y la recuperación observada en los '90, en general, no alcanzó para restaurar los niveles previos.

Los más altos niveles de acumulación en el pasado reciente parecen haberse alcanzado en el bienio 1997/98 en coincidencia con el momento de auge en el ingreso de capitales externos $^{24}$. En México, en cambio, la devaluación de fines del ' 94 generó un auge exportador que contribuyó a mantener en alza la tasa de inversión hasta 2000 sin que ello permita alcanzar, no obstante, los registros históricos. Chile, por su parte, fue el país en que

${ }^{24} \mathrm{El}$ aporte del ahorro externo al financiamiento del gasto en la región alcanzó su máximo nivel en 1998 con 4,3\% del PBI. 
más temprano comenzó a recuperarse la tasa de inversión luego de la crisis de la deuda y el único en que llegaron a superarse, en los '90, los (muy bajos) niveles históricos previos.

A finales de los '90 comenzó un nuevo retroceso en materia de inversión en la región y, esta vez sí, la acumulación se desaceleró también en Chile.

En suma, en general, la tasa de acumulación no se recuperó por completo de la contracción registrada en los '80. Como se afirma en UNCTAD (2003, 123); “las reformas han fracasado en crear las condiciones necesarias para iniciar un proceso rápido de acumulación de capital'.

\section{Evolución de la inversión extranjera}

Con la crisis de la deuda en 1982 se cerró también un largo ciclo de IED que había comenzado en los '50. En Argentina, Chile y México esta reversión tuvo efectos devastadores en términos del stock de capital y empleo, especialmente en aquellas ramas en que las empresas transnacionales mantenían una presencia sustancial (Bielschowsky y Stumpo, 1996). Los países atrasados pasaron de recibir casi la mitad de la IED mundial en 1982 al 15\% en 1989 (UNCTAD, 2000: 20).

Como se aprecia en el cuadro B2, al igual que la inversión doméstica, también la IED comenzó a recuperarse en la segunda mitad de los ' 80.

Cuadro 2: Inversión extranjera directa

(en millones de dólares, promedio anual)

\begin{tabular}{lrrrrrrr}
\hline & $1980 / 81$ & $1982 / 84$ & $1985 / 89$ & $1990 / 94$ & $1995 / 99$ & $2000 / 01$ & $2002 / 04^{\mathrm{b}}$ \\
\hline Argentina & 866 & 236 & 730 & 2.908 & 8,438 & 5,761 & 972 \\
Brasil & 1.929 & 1.836 & 1.166 & 1.035 & 17,966 & 27,607 & 10,367 \\
Chile & 298 & 201 & 714 & 832 & 3,808 & 1,732 & 3,447 \\
Colombia & 140 & 471 & 531 & 763 & 2,335 & 2,281 & 1,445 \\
México & 2.584 & 1.878 & 2.000 & 5.409 & 11,299 & 19,611 & 12,393 \\
Otros $^{\text {a }}$ & 202 & 52 & 153 & 1.221 & 3,689 & 2,521 & 2,659 \\
\hline Total países & 6.018 & 4.673 & 5.294 & 12.167 & 47,534 & 59,512 & 31,284 \\
seleccionados & & & & & &
\end{tabular}

${ }^{\mathrm{a}}$ Incluye Bolivia, Costa Rica, Jamaica y Perú. ${ }^{\mathrm{b}}$ Las cifras de 2004 son preliminares.

Fuentes: Hasta 1990/94: Moguillansky y Bielschowsky (op cit, 27, tabla I-2). Ultimos años: CEPAL (2004, 162, Cuadro A-16).

En los '90, por su parte, tuvieron lugar las siguientes fases:

- un aumento en la primera mitad de la década bajo el impulso de las inversiones externas dirigidas a Argentina, México y algunos países pequeños de la región.

- incremento en 1995/99, en todos los países. 
- en 2000/01 significativo aumento de la IED a Brasil y México y, al mismo tiempo, contracción de los flujos a Argentina y Chile.

- en 2002/04 desaceleración de la IED a la mayoría de los países grandes de la región.

Así, la fase alcista iniciada a mediados de los '90, que no tiene antecedentes en términos cuantitativos, alcanzó su máximo nivel en 1999 y se revirtió desde entonces; la IED se contrajo un $50 \%$ entre ese año y 2004. El país en que la oleada de IED adquirió mayor magnitud y se mantuvo durante un período más prolongado (1996/2002) fue Brasil. En Argentina y México, en cambio, el pico de ingresos duró un bienio (1999/2000 y 2000/01, respectivamente). En Chile se observó una aceleración de la IED en 1999 y en 2004, aunque el capital extranjero ingresó con relativa intensidad y estabilidad desde 1995.

La tabla 3 muestra que la IED aumentó más rápido que la tasa de inversión agregada en los países de destino. En ciertas naciones incluso (Brasil, Paraguay y Venezuela) en algunos años, la inversión privada declinó mientras la IED aumentó y en la mayoría el aumento de la razón IED/PBI fue muy superior a la relación entre inversión privada doméstica y el PBI (UNCTAD, 2003).

Cuadro 3 - Inversión extranjera directa

(\% de la inversión bruta fija)

\begin{tabular}{lrrrrrrr}
\hline & \multicolumn{1}{c}{$\begin{array}{c}\text { Prom } \\
1992 / 97\end{array}$} & 1998 & 1999 & 2000 & 2001 & 2002 & 2003 \\
\hline Argentina $^{\text {a }}$ & 11.2 & 12.2 & 46.9 & 22.6 & 5.7 & 6.4 & 1.9 \\
Brasil & 4.7 & 18.6 & 28.2 & 28.2 & 22.7 & 19.6 & 11.4 \\
Chile & 17.5 & 22.3 & 57.6 & 31.2 & 28.4 & 13.2 & 19.6 \\
Colombia & 12.3 & 15.2 & 13.2 & 22.8 & 21.8 & 17.7 & 15.5 \\
México & 14.4 & 14.0 & 13.0 & 13.4 & 21.5 & 11.8 & 8.9 \\
América latina y el Caribe & 10.1 & 17.4 & 25.6 & 21.1 & 19.8 & 14.9 & 11.2 \\
\hline a El porcentaje de 1999 refleja la privatización de YPF. Fuente. UNCTAD (2004, 391, Anexo B, tabla \\
B.5).
\end{tabular}

Dado que los datos de IED incluyen tanto la construcción de nuevas plantas como las operaciones de adquisición, no es posible relacionar directamente su nivel con la acumulación de capital en los países de destino. Lo notable es el desacople que manifiestan las corrientes de inversión extranjera directa respecto del impulso general de la acumulación en los países de destino. Así, en los años en que la IED experimentó una aceleración respecto de la acumulación de capital en los países de destino su peso llegó a representar un tercio y aún más de la inversión agregada. De hecho, mientras el peso de la IED en el PBI de América latina en los '90 fue 1,7 puntos más alto que en los '80, la tasa de inversión resultó 0,6 puntos más baja. Esto sugiere que la llegada del capital extranjero no estuvo relacionada con un proceso generalizado de acumulación de capital (UNCTAD, 2003) sino de aumento de la concentración y extranjerización.

Los datos ponen también de manifiesto el proceso de desplazamiento del capital privado nacional por parte del capital extranjero en América latina, en particular en el 
período de intensificación de la IED desde mediados de los '90 ${ }^{25}$. Esta cuestión se trata con cierto detalle en el apartado IV.

\section{Composición de la inversión}

En los '80 no sólo disminuyó la tasa de inversión sino que aumentó en ella el peso de sus componentes menos productivos.

Como se aprecia en la tabla, en todos los países seleccionados excepto Chile, la construcción residencial incrementó su peso relativo luego de la crisis de la deuda. Y se observa también el importante rol que jugó ese rubro en el aumento de la tasa de inversión en los '90 en Argentina y Colombia.

Cuadro 4 - Estructura de la inversión en América Latina (\% de la Inversión bruta fija total)

\begin{tabular}{lrccrr}
\hline \multicolumn{5}{c}{ Maquinaria y equipos } \\
\hline Argentina & 34,5 & 41,5 & 44,9 & 39,2 & 39,2 \\
Brasil & 37,1 & 30,3 & 31,6 & 31,2 & 37,3 \\
Chile & 46,7 & 34,8 & 35,4 & 41,1 & 44,8 \\
Colombia & 46,0 & 41,7 & 43,2 & 50,0 & 52,2 \\
México & 43,9 & 35,9 & 38,9 & 46,0 & 48,2 \\
\hline \multicolumn{5}{c}{ Construcción no residencial } \\
\hline Argentina & 28,8 & 19,9 & 15,1 & 16,2 & 15,8 \\
Brasil & 40,6 & 42,9 & 41,7 & 41,9 & 38,2 \\
Chile & 32,3 & 46,6 & 44,4 & 37,8 & 34,2 \\
Colombia & 39,8 & 42,5 & 39,6 & 29,3 & 27,1 \\
México & 38,0 & 39,2 & 31,8 & 25,2 & 23,0 \\
\hline \multicolumn{5}{c}{ Construcción residencial } \\
\hline Argentina & 36,8 & 38,6 & 39,9 & 44,6 & 45,0 \\
Brasil & 22,3 & 26,9 & 26,7 & 26,8 & 24,4 \\
Chile & 21,0 & 18,5 & 20,2 & 21,1 & 20,9 \\
Colombia & 14,2 & 15,7 & 17,2 \\
México & 18,1 & 24,9 & 29,3 & 20,7 \\
\hline Nota; la suma de los tres rubros es 100\% excepto algunos casos en que se \\
observan diferencias de $\pm 0,1 \%$ por redondeo de datos en el original. \\
\hline Fuente: UNCTAD (2003, 81, tabla 4.2).
\end{tabular}

25/ En UNCTAD $(2003,78)$ se reseñan algunos estudios empíricos que sugieren que América latina era ya en los ' 80 y en la primera mitad de los '90 la región en que se presentaban con mayor intensidad los efectos de crowding out entre ambas fuentes de capital. 
Se ocultan detrás de este fenómeno, dos cuestiones. Uno, en algunos países (Argentina y Chile), una recuperación muy débil de la inversión en maquinaria y equipos respecto de los niveles históricos. Dos, una caída generalizada de la construcción no residencial, es decir; de las inversiones más directamente ligadas con la expansión de la capacidad productiva y la infraestructura.

En un estudio reciente sobre la inversión en América latina en los '90 (Moguillansky y Bielschowsky, op cit) se concluye que luego de la implementación de las llamadas reformas estructurales se sucedieron dos fases.

- En la primera, las empresas disminuyeron sus gastos de inversión y avanzaron en la racionalización de personal. Por ejemplo, en Argentina esto ocurrió en los '70 y '80 luego de la primera tanda de reformas y de la crisis de la deuda y se repitió nuevamente a principios de los ' 90 , luego de la segunda tanda.

- En la segunda, realizaron inversiones puntuales en nuevas máquinas y equipos más modernos cuya rentabilidad resultaba, pese a las tasas de interés domésticas relativamente elevadas, atractiva en esta coyuntura, por dos razones. Por un lado, el reemplazo de equipos obsoletos prometía un aumento significativo de la productividad laboral. Por el otro, las reformas económicas habían disminuido los precios de los bienes de capital con respecto a los de la fuerza de trabajo. Además, las empresas se encontraban en general ante la necesidad de disminuir sus costos para operar en el nuevo escenario.

En suma, podría afirmarse que el aumento de la productividad ocasionado por la racionalización y la modernización de los equipos en los primeros años de la década de los '90 no evolucionó hacia un proceso de inversión basado en la expansión de la capacidad productiva. Así, las inversiones realizadas sólo permitieron una parcial modernización de los equipos, alentada por el abaratamiento del costo del capital provocado por la apertura, la apreciación y el aumento del nivel de actividad.

\section{Orientación sectorial}

En varios países de la región se ha observado que, más que reorientarse hacia actividades distintas, la inversión se des-diversificó, concentrándose en ramas que ya atraían una porción sustancial de la acumulación en los años '70. En efecto, los seis sectores que habían resultado más importantes en materia de inversión en 1970/88 en Brasil no sólo son los mismos que acaparan el grueso de la inversión en 1995/97 sino que su peso relativo pasó de $44 \%$ a 57\% entre ambos períodos. Algo similar ocurrió en Chile donde los mismos siete sectores pasaron de absorber $80 \%$ en 1979/85 a explicar $85 \%$ de la inversión total en 1990/95. En México los mismos cinco sectores más importantes incrementaron su peso en la inversión agregada desde 37\% en 1970/85 a 53\% en 1991/94. En Colombia, por último, los primeros siete rubros en 1970/89, que explicaban 45\% de la inversión, lideraban también en 1992/95 pero ahora absorbían 59\% de la inversión (Moguillansky y Bielschowsky, op cit, 174-76, tabla A-7) ${ }^{26}$.

26/ En el mismo sentido, en este estudio se muestra que la mayoría de los rubros en que la tasa de crecimiento de la productividad se acelera (respecto de la de la misma rama en los EE.UU.) venían experimentando ya esta “convergencia” desde los años '80, esto es; antes de completadas las reformas. 
Dentro de este panorama general de des-dvr de la inversión se observó una expansión relativa de las actividades intensivas en trabajo y/o en recursos naturales. De un análisis de conjunto sobre la inversión en América latina en el período 1980/00 (UNCTAD, 2003) surge que las actividades más atractivas para la inversión resultaron las siguientes:

-servicios; telecomunicaciones, energía y finanzas,

- commodities industriales basados en recursos naturales (pulpa y papel, hierro y acero, aceites vegetales)

- ensamble de equipos electrónicos, TV, video y vestimenta

- automotriz, que gozó de una política específica en los países en que está radicada

El grado de dinamismo de la inversión en estos rubros en los distintos países puede comprenderse de un modo sistemático teniendo en cuenta que las llamadas "reformas estructurales" potenciaron dos patrones de organización e inversión industrial:

- aquellos países localizados cerca de los EE.UU. (geográficamente o por medio de acuerdos comerciales) como México y los pequeños países de Centro América, expandieron sus actividades de maquila dedicadas al ensamble de productos electrónicos, automóviles etc. Estas fábricas producen casi exclusivamente para el mercado norteamericano o para la reexportación desde allí a terceros países y generan puestos de trabajo de bajos salarios y baja calificación. Las corporaciones transnacionales son las que comandan estas redes de producción internacional, aunque actúan también algunas grandes compañías nacionales vinculadas con ellas

- los países grandes de Sudamérica (Argentina, Brasil y Chile) expandieron y elevaron la intensidad de capital de sus ramas basadas en recursos naturales

Una apreciación general acerca de la orientación sectorial de la inversión en las últimas dos décadas podría resumirse así; mientras que, por un lado, las actividades manufactureras han perdido peso como destino de la inversión, por el otro, ningún negocio alternativo, tomado individualmente, ha atraído montos significativos de inversión. " $E l$ aumento de la competencia internacional a la que están expuestos los países de América latina destruyó una parte de la industrialización que se había logrado en condiciones de alta protección, sin al mismo tiempo poner en marcha un proceso de creación de algo nuevo" (UNCTAD, 2003: 102).

En suma, la escasez de opciones rentables de inversión en América latina se presenta como un fenómeno notorio, a través de dos características del proceso de inversión. En primer lugar, el pobre comportamiento de la acumulación global. En segundo lugar, la relativa des-diversificación de los principales destinos de la inversión, observada en algunos estudios ${ }^{27}$.

${ }^{27}$ Existe todavía un síntoma adicional; las reducidas perspectivas de crecimiento y rentabilidad que prometen muchas de las inversiones efectivizadas. Pero esta cuestión se trata con mayor detalle en el apartado III sobre los obstáculos al crecimiento rentable que enfrentan las grandes empresas de América latina. 


\section{Orientación de mercado}

Este inciso comprende dos aspectos; las inversiones de empresas de América latina fuera de sus países de origen (que es tratada directamente en varios incisos de este capítulo) y las inversiones realizadas en sus países en actividades exportadoras.

Entre los países más grandes de América latina se observó un cierto incremento de la inversión en actividades exportables en las últimas dos décadas. Lo que no implica que no se hayan registrado diferencias de grado y, como se comentó en un inciso previo, en la orientación sectorial específica.

Los casos de viraje más drástico son los de Chile y México, donde la inversión se orientó de un modo predominante hacia la producción exportable. El giro de la inversión hacia las actividades exportadoras se consolidó en Chile en 1986/89 en una gran diversidad de ramas y prosiguió en los '90 aunque en un número acotado de rubros (asociados con los recursos naturales). En México, por su parte, la primera oleada importante de inversiones en las ramas de ensamble (autos, computación, electrónica y confección) tuvo lugar en los ' 80 y principios de los '90. Más tarde, habría una segunda fase de inversiones del mismo tipo, estimuladas por la devaluación del peso mexicano ocurrida fines de 1994. En contraste, fue más tenue el giro en Brasil, donde la inversión estuvo orientada principalmente hacia actividades asociadas con la demanda interna y sólo marginalmente al mercado externo ${ }^{28} \%$. El caso intermedio fue el de Argentina, porque allí la escasa inversión en nueva capacidad estuvo asociada tanto con el mercado interno como con las exportaciones.

En suma, de un modo general, se aprecia un aumento de las exportaciones industriales entre los '90 y los '80 en los países más grandes de América latina (aunque en Chile desde una base muy pequeña) siguiendo un patrón similar al que siguió la inversión en general; la participación en redes internacionales de producción (bajos costos laborales) y las manufacturas ligadas con la explotación de recursos naturales (ventajas comparativas).

\section{Conclusión}

Finalmente, las principales conclusiones de este Anexo pueden resumirse así. La región tuvo un desempeño muy pobre en materia de inversión desde la crisis de la deuda a principios de los años '80. En los '90 se observó una recuperación pero resultó débil y comprendió a un número menor de actividades que en la década de los '70. Tuvo lugar también una entrada masiva de inversión directa del exterior, en particular después de 1995 que, más que acoplarse a una expansión generalizada liderada por el capital nacional, reposó en la adquisición de activos productivos del estado y las empresas de capital local.

\footnotetext{
${ }^{28}$ Ciertamente, las exportaciones literalmente se dispararon en 2003 y han comenzado a crecer a tasas elevadas desde entonces. Pero no puede decirse que haya tenido lugar un proceso significativo de inversiones en rubros orientados al mercado externo.
} 
Las ramas que atrajeron relativamente más inversión han sido las intensivas en mano de obra no calificada y el procesamiento de recursos naturales y se ha observado, en la mayoría de los países, un aumento de la producción exportable. 